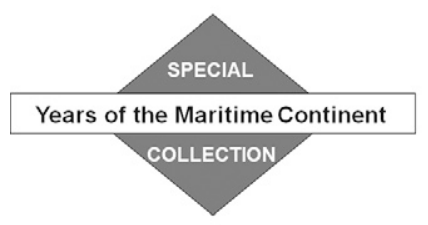

\title{
OOn the Sensitivity of the Simulated Diurnal Cycle of Precipitation to 3-Hourly Radiosonde Assimilation: A Case Study over the Western Maritime Continent
}

\author{
Joshua Chun Kwang Lee, ${ }^{\mathrm{a}}$ Anurag Dipankar, ${ }^{\mathrm{a}}$ AND XIAng-Yu Huang ${ }^{\mathrm{a}}$ \\ ${ }^{\text {a }}$ Centre for Climate Research Singapore, Meteorological Service Singapore, Singapore
}

(Manuscript received 24 December 2020, in final form 24 June 2021)

\begin{abstract}
The diurnal cycle is the most prominent mode of rainfall variability in the tropics, governed mainly by the strong solar heating and land-sea interactions that trigger convection. Over the western Maritime Continent, complex orographic and coastal effects can also play an important role. Weather and climate models often struggle to represent these physical processes, resulting in substantial model biases in simulations over the region. For numerical weather prediction, these biases manifest themselves in the initial conditions, leading to phase and amplitude errors in the diurnal cycle of precipitation. Using a tropical convective-scale data assimilation system, we assimilate 3-hourly radiosonde data from the pilot field campaign of the Years of Maritime Continent, in addition to existing available observations, to diagnose the model biases and assess the relative impacts of the additional wind, temperature, and moisture information on the simulated diurnal cycle of precipitation over the western coast of Sumatra. We show how assimilating such high-frequency in situ observations can improve the simulated diurnal cycle, verified against satellite-derived precipitation, radar-derived precipitation, and rain gauge data. The improvements are due to a better representation of the sea breeze and increased available moisture in the lowest $4 \mathrm{~km}$ prior to peak convection. Assimilating wind information alone was sufficient to improve the simulations. We also highlight how during the assimilation, certain multivariate background error constraints and moisture addition in an ad hoc manner can negatively impact the simulations. Other approaches should be explored to better exploit information from such high-frequency observations over this region.
\end{abstract}

KEYWORDS: Maritime Continent; Tropics; Radiosonde/rawinsonde observations; Data assimilation

\section{Introduction}

The diurnal cycle is the most prominent mode of rainfall variability in the tropics. Strong solar heating and resulting energy fluxes between the land surface, adjacent seas, and the atmosphere in the afternoon often create a moist and unstable environment that is favorable for convection. Regional variations in the diurnal cycle exist and may be attributed to topography and orographic forcing (Ohsawa et al. 2001; Yang and Slingo 2001; Qian 2008). For the western Maritime Continent, precipitation typically peaks in the late afternoon over land, and in the early morning over open sea. Over the coasts, the land-sea interaction is altered by significant orography. For example, over the western coast of Sumatra, the impinging of the sea breeze on orography typically leads to an early afternoon convective peak over the mountains, which propagates either inland or offshore

\footnotetext{
D Denotes content that is immediately available upon publication as open access.
}

Corresponding author: Joshua Chun Kwang Lee, joshua_lee@ nea.gov.sg depending on the lower tropospheric conditions and season (Mori et al. 2004; Sakurai et al. 2005; Sakurai et al. 2009; Yanase et al. 2017). During the offshore propagation, the convective cells reach the foot of the mountains in the late afternoon, before migrating farther over the coastal sea during the night.

These physical processes involved occur throughout the western Maritime Continent, but given the cornucopia of islands and complex topography, are often challenging for both numerical weather prediction (NWP) and climate models to represent. Studies have suggested that the poor representation of the topography along the coastal region in coarse resolution models affects the land-sea interactions crucial for initiating convection (Qian 2008; Takayabu and Kimoto 2008; Sato et al. 2009; Love et al. 2011; Hassim et al. 2016; Rashid and Hirst 2017; Im and Eltahir 2018). Other studies have suggested that more complex processes such as the interaction of cumulus convection with the large-scale motions, propagation of gravity waves and underlying air-sea interactions may not be properly represented and are constrained by limitations in the model physics (Wang et al. 2007; Gianotti et al. 2012; Teo et al. 2011; Birch et al. 2015; Bhatt et al. 2016). Consequently, NWP and climate models may develop substantial biases in key model variables related to wind, temperature, and moisture. 
Particularly for NWP, these biases manifest themselves in the initial conditions and can result in phase and amplitude errors in the simulated diurnal cycle of precipitation. Over the western coast of Sumatra, Dipankar et al. (2019) speculated that the related temperature and moisture biases in the initial and boundary conditions resulted in a delayed and weaker simulated mean diurnal cycle of precipitation when compared to surface observations. Typically, one may employ data assimilation to diagnose and correct such biases to retrieve the best estimate of the initial conditions. However, it is often not trivial due to the temporal and spatial variation of the biases, and also mainly due to the lack of observations over the western Maritime Continent. Specifically over the Malay Peninsula and Sumatra, there are only slightly more than ten radiosondes launched regularly, twice a day (0000 and 1200 UTC), which provide in situ observations of wind, temperature and moisture. These radiosondes barely provide sufficient coverage for the region and the convective-scale phenomena that occur within it, let alone of their diurnal variation.

In recent years, multiple intensive observation projects have been conducted over the region (see Table 1 of Yoneyama and Zhang 2020). Apart from allowing better understanding of the diurnal cycle of precipitation and the mechanisms governing it, such observations can also be assimilated in an NWP system to help diagnose the model biases and study the impact of correcting them-particularly for wind, temperature and moisture biases. However, one should be aware that there are known limitations when assimilating atmospheric water-related observations [see Bannister et al. (2020) for a review, and references therein] and any multivariate relationships prescribed in the corrections are subject to background error constraints of the data assimilation system. These limitations should be carefully scrutinized as they could lead to assimilation suboptimalities. It is therefore reasonable to expect that the best estimate of the initial conditions after data assimilation may still not be optimal and can thus affect the simulated diurnal cycle of precipitation.

The choice of focusing on the diurnal cycle of precipitation over the western coast of Sumatra is twofold. First, an intensive observation project known as the pilot field campaign of the Years of the Maritime Continent (Pre-YMC) was conducted (Yokoi et al. 2017; Yoneyama and Zhang 2020) toward the end of 2015 over the region, providing high frequency observations and the opportunity for assimilation experiments, possibly using radiosonde or radar data. Second, the combination of nearby orographic and coastal effects, along with a readily convective environment increases the complexity of performing accurate simulations over the region, which could perhaps be considered a rigorous "stress-test" for convectivescale data assimilation to highlight any major deficiencies.

Radiosonde assimilation sensitivity experiments and such "stress-tests" are not particularly new. Lorenc et al. (1996) previously diagnosed the biases over the United Kingdom using radiosonde data and tested various data assimilation configurations to gain insights on their weaknesses. Faccani et al. (2009) and Sun et al. (2020) assessed the impact of assimilating additional radiosonde data on forecasts over western Africa and Antarctica, respectively. However, despite the availability of data from recent intensive observation projects over the western Maritime Continent, such case studies in this region are still absent.

Here, we perform a case study over western the Maritime Continent, building on previous work by Dipankar et al. (2019). By assimilating the high frequency radiosonde data available from the Pre-YMC field campaign in addition to existing available observations, we conduct "variable denial" experiments (VDEs) in a tropical convective-scale data assimilation system, whereby only certain variables from the radiosonde data are assimilated for each VDE. These experiments are partly inspired by the approach of Žagar et al. (2004a,b), who assimilated either wind or mass information in observing system simulation experiments to assess their relative importance in the tropics. The aim of the VDEs is to investigate the relative impacts of assimilating radiosonde wind, temperature and moisture information on the simulated diurnal cycle of precipitation over the western coast of Sumatra, as well as highlight any deficiencies that may occur as a result of the known limitations of the system.

Section 2 contains details on the observations, the VDEs and scope of this case study. We diagnose and compare the shortrange model biases and analysis increments between VDEs (section 3), verify the simulated diurnal cycle of precipitation over the western coast of Sumatra from the VDEs (section 4), discuss limitations of the system (section 5) and summarize our conclusions (section 6).

\section{Observations, model, and scope}

\section{a. Pre-YMC field campaign}

The Pre-YMC field campaign is a pilot field campaign of the YMC project (Yoneyama and Zhang 2020), an international project lasting from 2017 to 2019, consisting of many intensive observation projects focused on the Maritime Continent conducted by the Japan Agency for Marine-Earth Science and Technology, the Indonesian Agency for the Assessment and Application of Technology, and the Indonesian Agency for Meteorology, Climatology and Geophysics. As part of the PreYMC field campaign, 3-hourly radiosonde observations and continuous measurements of basic surface meteorological variables were performed from two observation sites: a coastal city, Bengkulu, Sumatra; and the Research Vessel (R/V) Mirai, deployed about $50 \mathrm{~km}$ off the coast of Bengkulu from 22 November to 24 December 2015. These two observation sites lie on a line that is approximately perpendicular to the western coast of Sumatra, adjacent to the Sumatran mountain range running from northwest to southeast (Fig. 1). Additionally, a dual-polarized C-band Doppler radar was deployed at R/V Mirai which obtained volume scan data at 6 -min intervals with a ray spacing of $0.7^{\circ}-1^{\circ}$ (based on elevation angles) and gate spacing of $150 \mathrm{~m}$, at 17 elevation angles ranging from $0.5^{\circ}$ to $40^{\circ}$ with a range of $100 \mathrm{~km}$.

From 3-hourly radiosonde observations, one can derive information on the vertical profile of wind, temperature, and moisture which is reported as relative humidity $(\mathrm{RH})$, and be able to distinguish clear diurnal signals in the vertical profiles, as shown in Yokoi et al. (2017). From the continuous surface measurement of precipitation, one can also diagnose and verify 
(a)

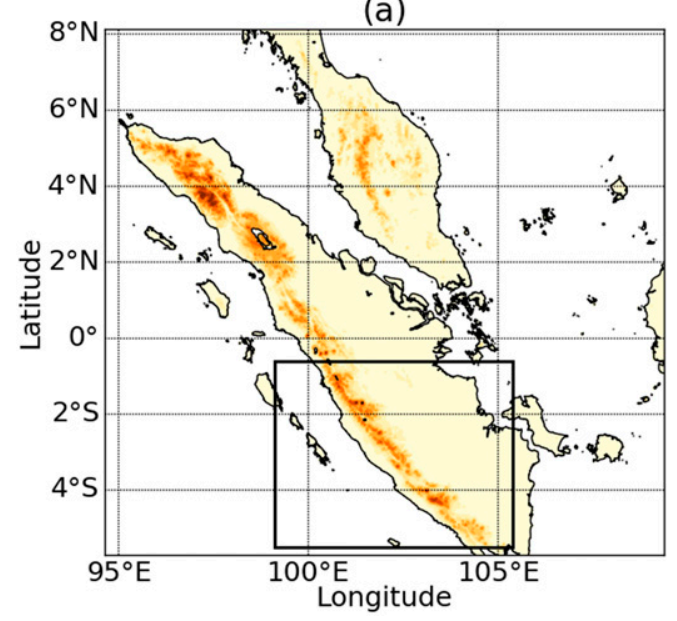

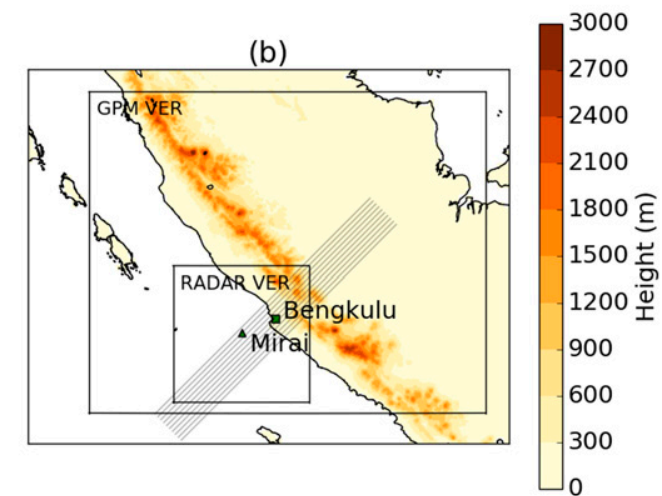

FIG. 1. (a) The simulation domain and (b) a zoom-in, enclosed by rectangle in (a), on part of the western coast of Sumatra revealing the Bengkulu (square) and R/V Mirai (triangle) observation sites along transects (gray) approximately perpendicular to the coast. The verification domain using satellite-derived precipitation (GPM VER) and radar-derived precipitation (RADAR VER) is also indicated in (b). The shadings indicate the orography in the simulation domain.

the diurnal signal, although surface measurements at one point cannot represent the overall spatial distribution of precipitation. One may also utilize radar-derived precipitation from Mirai, as well as existing satellite-derived precipitation products for verification purposes.

Yokoi et al. (2017) found that the diurnal signals in the western Maritime Continent can be influenced by propagating tropical modes such as the Madden-Julian oscillation (MJO). Thus, following Dipankar et al. (2019), we retain observations from the period when the diurnal signals were not disrupted by the MJO (23 November-12 December 2015) for comparison with the model simulations.

\section{b. Model setup and overview of VDEs}

The model setup builds on the framework described in Dipankar et al. (2019), which entails the use of SINGV (Dipankar et al. 2020), a tropical convective-scale data assimilation system developed from the Met Office Unified Model (UM), run at $1.5-\mathrm{km}$ horizontal resolution over the western Maritime Continent and centered on Singapore. We use the same simulation domain as Dipankar et al. (2019), shown in Fig. 1a, which is the standard simulation domain for NWP applications at the Meteorological Service Singapore. The numerical model configuration is similar to the configuration used in Dipankar et al. (2019).

With recent advances in SINGV development, a variant of SINGV with data assimilation capability (SINGV-DA; Huang et al. 2019; Heng et al. 2020) has been developed. Using SINGV-DA, we run 3-hourly cycling 3D-Var First-Guess-atAppropriate-Time (FGAT) data assimilation simulations to assess the impact of assimilating additional wind, temperature and moisture information from Bengkulu and Mirai radiosondes in conjunction with existing observations (Heng et al. 2020) which include satellite, aircraft and other radiosonde data in the domain from the Global Telecommunication System. A series of five VDEs are performed, with their differences detailed and abbreviated in Table 1.

For both Bengkulu and Mirai radiosondes, we use the same observation error profiles as other radiosondes in the domain, adopting values used at the United Kingdom Met Office over the same domain. For each radiosonde ascent, we have

TABLE 1. Comparison of the setup for the five VDEs; zonal wind $(u)$, meridional wind $(v)$, temperature $(T)$, and relative humidity $(\mathrm{RH})$ information from Bengkulu and Mirai radiosondes that are assimilated are indicated in the table with an $\times$ symbol. Existing observations in SINGV-DA are described in Heng et al. (2020), which include satellite, aircraft, and other radiosonde data in the domain from the Global Telecommunication System.

\begin{tabular}{lcccc}
\hline \hline & \multicolumn{4}{c}{ Assimilated information } \\
\cline { 2 - 5 } Abbreviation & $\begin{array}{c}\text { Existing } \\
\text { observations }\end{array}$ & $\begin{array}{c}\text { Bengkulu and Mirai } \\
\text { radiosondes } u \text { and } v\end{array}$ & $\begin{array}{c}\text { Bengkulu and Mirai } \\
\text { radiosondes } T\end{array}$ & $\begin{array}{c}\text { Bengkulu and Mirai } \\
\text { radiosondes RH }\end{array}$ \\
\hline CTRL & $\times$ & & & \\
EXPT_uv & $\times$ & $\times$ & $\times$ \\
EXPT_T & $\times$ & $\times$ & $\times$ & \\
EXPT_uvT & $\times$ & $\times$ & $\times$ & $\times$ \\
EXPT_uvTRH & $\times$ & & \\
\hline
\end{tabular}



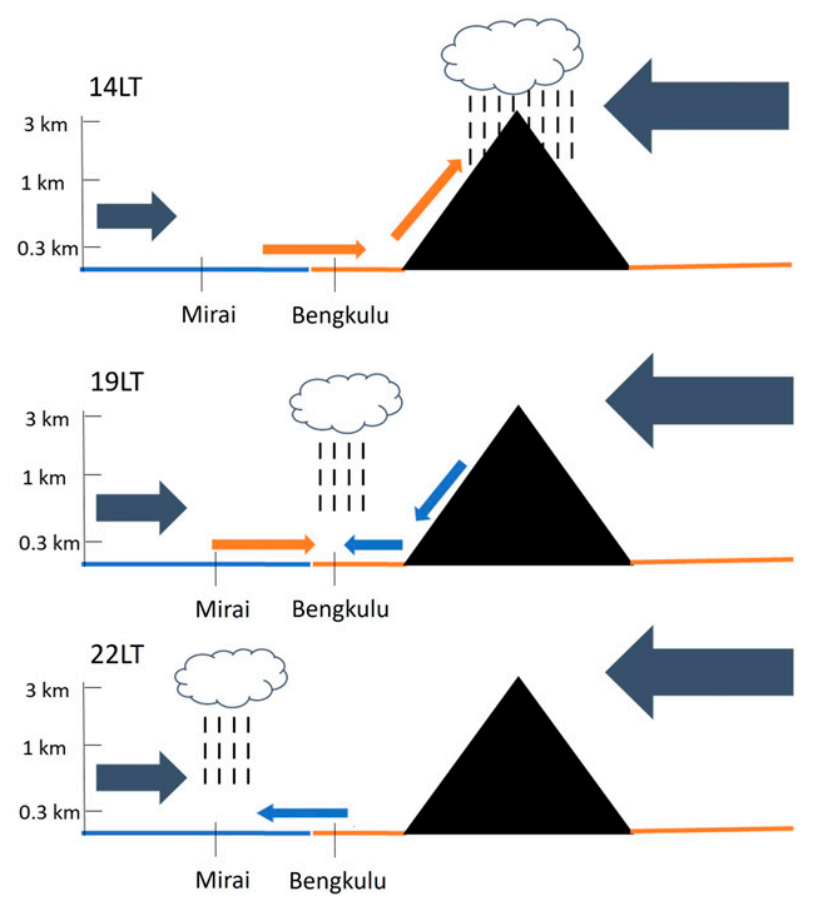

FIG. 2. Schematics of the transect-height cross sections showing the mechanisms behind the typical development of precipitation at (top) 1400 and (middle) $1900 \mathrm{LT}$ over adjacent mountains and Bengkulu, and (bottom) its subsequent propagation offshore to Mirai at 2200 LT. The gray, orange, and blue arrows represent the prevailing winds, sea breeze, and cold pool, respectively.

interpolated the profile to pressure levels every $5 \mathrm{hPa}$. Further standard online quality control procedures are also applied which include buddy checks and consistency checks at each pressure level.

The simulations for these VDEs are run from 23 November to 12 December 2015, are full-cycling, and use lateral boundaries from European Centre for Medium-Range Weather Forecasts (ECMWF) forecasts and analyses at 0000 and 1200 UTC. For each of the eight cycles, a 24-h forecast is produced. To account for the spinup of the 3-hourly cycling data assimilation system, the forecasts from the first day (23 November 2015; eight cycles) are excluded.

\section{c. Scope of case study}

The diurnal variability of precipitation over the region (Fig. 1b) is characterized by the development of precipitation near Bengkulu and its subsequent offshore propagation toward and across Mirai. Figure 2 is a schematic showing the processes involved, based on previous work by Mori et al. (2004), Hassim et al. (2016), Yokoi et al. (2017) and Dipankar et al. (2019). Typically, the arrival of the sea breeze at 1400 LT generates heavy precipitation over the adjacent mountains, which forms a cold pool that interacts with the prevailing near-surface westerlies and triggers convection over Bengkulu. This cold pool advances seaward and induces near-surface convergence at its leading edge, resulting in the offshore propagation of precipitation past Mirai at around 2200 LT. The extent of

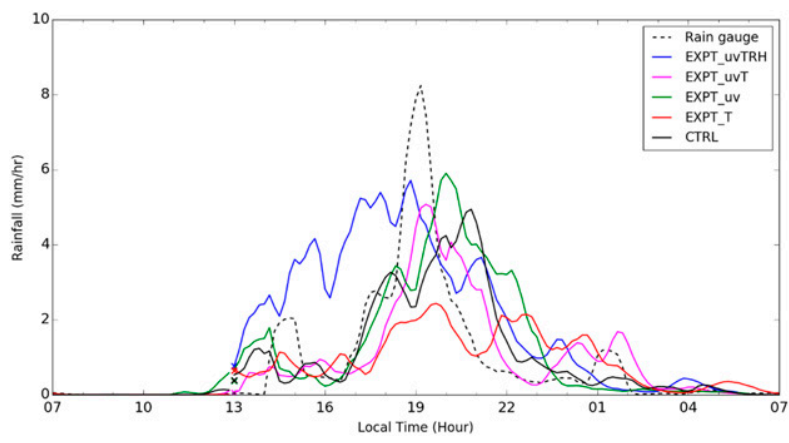

FIG. 3. Mean diurnal cycle of precipitation from the five VDEs compared with rain gauge data from Bengkulu for simulations initialized at $1300 \mathrm{LT}$. The cross indicates the mean 3-h forecast of precipitation from the previous cycle.

propagation can be influenced by the large-scale offshore environment (Coppin and Bellon 2019), preconditioned by the gravity waves generated from the daytime convective heating (Yokoi et al. 2017; Bai et al. 2021).

There are two aspects of this diurnal variability that models may fail to accurately represent - the timing and intensity of the triggered convection near Bengkulu, and its subsequent offshore propagation toward and across Mirai.

To briefly illustrate the first aspect, we compare the observed (rain gauge) and simulated (simulations initialized at 1300 LT) mean diurnal cycle of precipitation over Bengkulu (Fig. 3). One may note how the simulated diurnal cycle from some of the VDEs tends to be delayed and weaker, in accordance with Dipankar et al. (2019). A more detailed verification is performed in section 4 along with a description on the rain gauge data processing.

To briefly illustrate the second aspect, we compare Hovmöller diagrams (Fig. 4) of the observed [Global Precipitation Mission (GPM)] and simulated (simulations initialized at $1300 \mathrm{LT}$; hourly accumulated) precipitation averaged across transects perpendicular to the Sumatran coast (see Fig. 1b). One may note how the simulated offshore propagation from the VDEs are not as clearly defined as in GPM; the precipitation does not propagate farther offshore past Mirai. More information on the GPM data and further verification can also be found in section 4.

In this case study, we focus mainly on the first aspect: model biases over Bengkulu and their impact on the simulated timing and intensity of the triggered convection near Bengkulu (sections 3a-c). We have also included some comments on the second aspect: Model biases over Mirai and possible implications on the subsequent offshore propagation of precipitation (section 3d).

\section{Model biases and analysis increments in VDEs}

We first diagnose the short-range model biases and corrections known as analysis increments - as a result of assimilating additional Pre-YMC radiosonde data in SINGV-DA. The model biases can be diagnosed using background minus observation $(B-O)$ statistics, where the background refers to the 3 -h forecast 

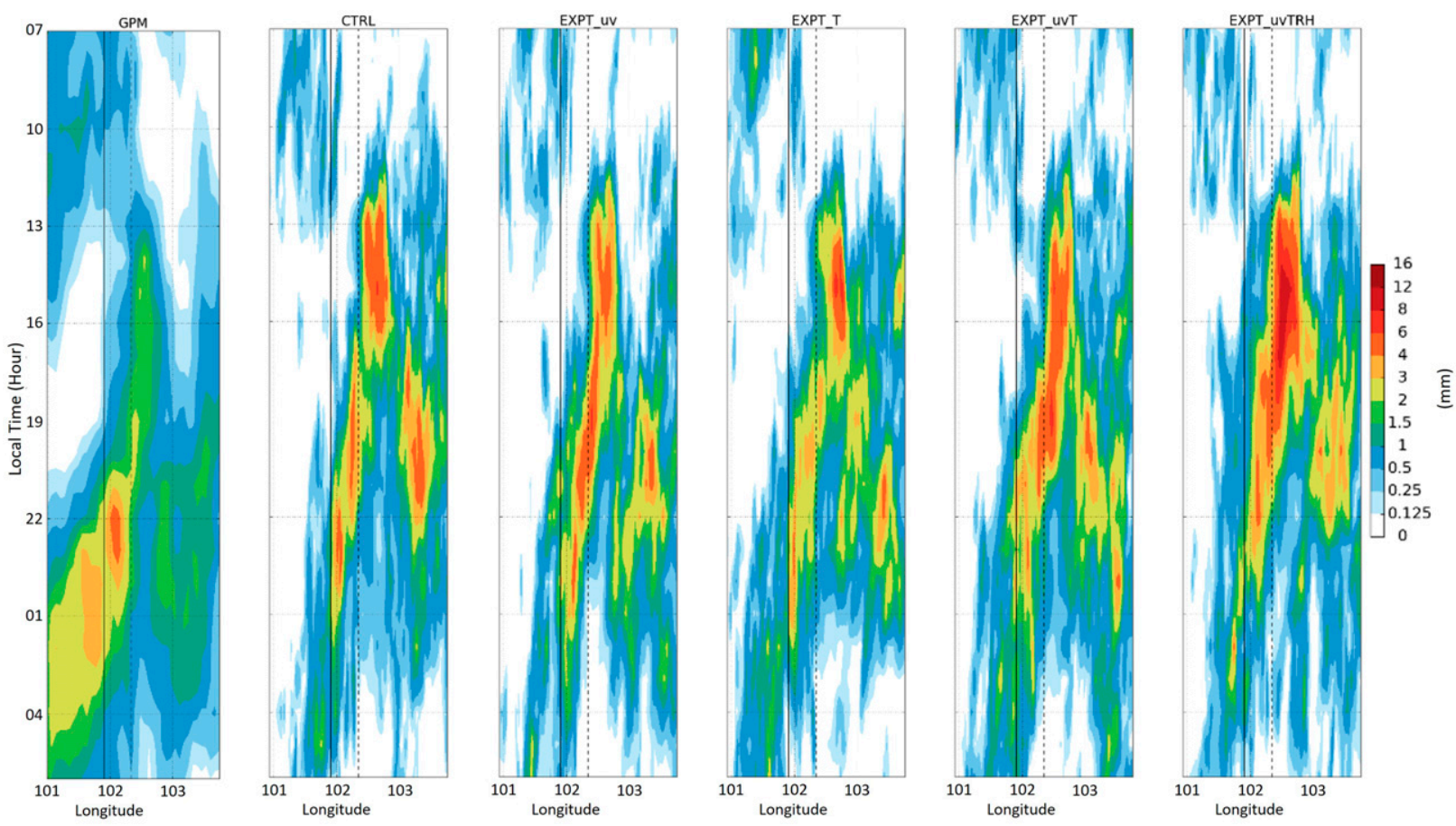

FIG. 4. Hovmöller diagrams of the mean diurnal cycle of precipitation along the transect perpendicular to the Sumatran coastline. Hourly accumulated precipitation from simulations initialized at 1300 LT from the five VDEs are compared to GPM data. The dotted and solid lines indicate the longitudinal position of Bengkulu and R/V Mirai, respectively.

from the previous cycle. The model value is interpolated to observation locations and $B-O$ is computed for each cycle for all VDEs. For CTRL, while $B-O$ is computed, the observations are not eventually assimilated. These biases may exhibit temporal and spatial variability, so focus is placed on the mean diurnal variation to be consistent with the mean diurnal cycle of precipitation (section 4). Over Bengkulu, we also compute the analysis increments (analysis minus background; $A-B$ averaged in a $20-\mathrm{km}$ square domain around Bengkulu) and compare the implications for each cycle when information about certain variables are omitted.

\section{a. 3- $h$ biases and analysis increments in horizontal wind over Bengkulu}

For the horizontal wind biases, the biases in wind speed and direction are both important. They are computed by considering the resultant of the zonal and meridional wind biases. As an example, given the northwest-to-southeast orientation of the coast, a northeasterly wind bias indicates that the offshore wind is too strong in the model compared to observations, and is referred to as an offshore wind bias. It can also be interpreted as an onshore wind that is too weak in the model compared to observations, because the biases are not indicative of the actual wind direction and speed.

In the five VDEs, there exists an offshore wind bias of about $2 \mathrm{~m} \mathrm{~s}^{-1}$ in the boundary layer (below $1 \mathrm{~km}$ ) around 1000 to $1300 \mathrm{LT}$ (Fig. 5, top panel). At $1600 \mathrm{LT}$, the bias is approximately onshore instead. The onshore wind bias is similarly found in Fig. 7a of Dipankar et al. (2019) when comparing the along transect wind (southwesterly) with the daily mean wind. The offshore wind bias in the boundary layer is likely related to the onset of the sea breeze occurring below $1 \mathrm{~km}$ around 1000 to 1300 LT along the western coast of Sumatra (Mori et al. 2004). The bias suggests that the onshore sea breeze is too weak in the model, possibly closely related to a cold bias which is further discussed in section 3b. A weaker sea breeze may result in weaker convection over orography, and subsequently over Bengkulu, as seen in Fig. 3.

There also exists a strong westerly wind bias of about $5 \mathrm{~m} \mathrm{~s}^{-1}$ in the lower troposphere (1-4 km) after peak convection from 1900 to $0100 \mathrm{LT}$. The strong westerly wind bias (approximately onshore) from 1900 to 0100 LT is consistent with Dipankar et al. (2019) where the daily mean along transect wind is too onshore in the model compared to observations. Notably, they also found that the speed of propagation of the precipitation offshore after 1900 LT was slightly slow, which is possibly associated with the westerly wind bias.

One would expect that resolving the offshore wind bias at 1000 to $1300 \mathrm{LT}$ would result in a better representation of the sea breeze, vital for accurately simulating the diurnal cycle of precipitation over Bengkulu. Resolving the westerly wind bias directly would help improve the propagation of convection away from the mountains, which is also an important aspect of the diurnal cycle.

Next, we assess the horizontal wind analysis increments around Bengkulu. Since the analysis increments over Bengkulu can be influenced by other assimilated observations, we compare EXPT_uv, EXPT_T, EXPT_uvT, and EXPT_uvTRH with CTRL as a baseline. In CTRL and EXPT_T, the analysis increments are negligible because very little wind information 

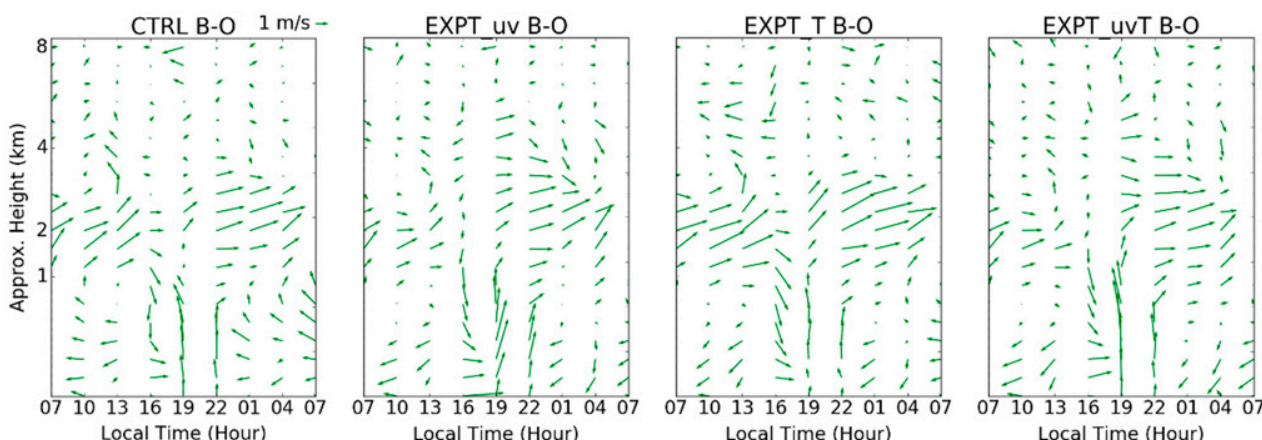
Local Time (Hour)

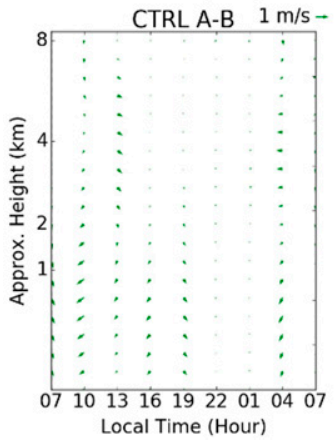
EXPT_uv A-B ocal Time (Hour)
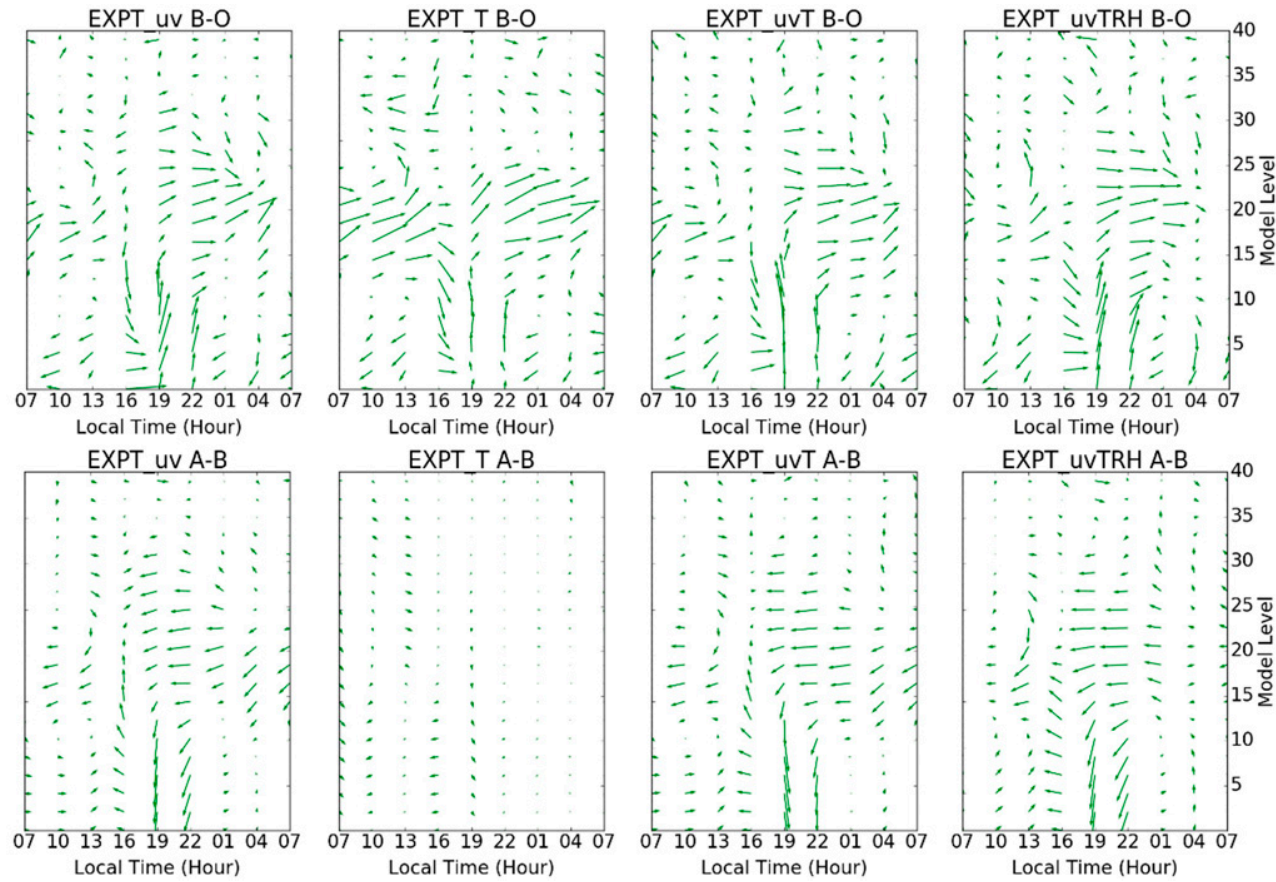

FIG. 5. Mean diurnal variation of (top) background minus observation $(B-O)$ vertical profiles of horizontal wind and (bottom) corresponding mean horizontal wind analysis increments $(A-B)$ at Bengkulu at initialization time for the five VDEs (from left to right) CTRL, EXPT_uv, EXPT_T, EXPT_uvT, and EXPT_uvTRH. Composites of vertical profiles for each VDE are taken according to the initialization time over the 19 days of the simulation period. The quivers represent the resultant horizontal wind direction and wind speed, indicated at every two model levels. A wind direction of $45^{\circ}$ (southwesterly) and $135^{\circ}$ (northeasterly) approximately indicates onshore and offshore winds at Bengkulu, respectively. Longer arrows indicate a larger wind speed.

from existing observations is available over Bengkulu (Fig. 5, bottom panel). In the other three VDEs, the additional wind information from Pre-YMC radiosonde data are assimilated. The wind analysis increments are generally opposite of the biases, indicating that the system is attempting to reduce the biases. In particular, the onshore wind from 1000 to 1300 LT is strengthened by around $1 \mathrm{~m} \mathrm{~s}^{-1}$ in the boundary layer and the easterly wind analysis increments of around $3 \mathrm{~m} \mathrm{~s}^{-1}$ are added in the lower troposphere from 1900 to $0100 \mathrm{LT}$.

We note that while the horizontal wind analysis increments appear reasonable and should help to better prescribe the initial conditions for simulating the diurnal cycle of precipitation, they did not substantially reduce the short-range horizontal wind biases. Without wind information, the magnitude of the biases for EXPT_T appear slightly larger than CTRL. Even with wind information, the diurnal variation of biases between EXPT_uv, EXPT_uvT, and EXPT_uvTRH are still relatively similar compared to CTRL. It is possible that within the duration of each 3-h forecast used as the background, the model may adjust back to a state that may be inconsistent with observations, and thus the biases tend to persist.

\section{b. 3-h biases and analysis increments in potential temperature over Bengkulu}

The temperature $(T)$ biases are converted to potential temperature $(\theta)$ using Exner pressure to have a more straightforward comparison with the analysis increments of $\theta$ and results of
Yokoi et al. (2017). The diurnal variation in the mean vertical profile of $T$ and $\theta$ biases are nevertheless very similar.

In the five VDEs, there exists a cold bias of around $2 \mathrm{~K}$ in the model in the morning to early afternoon prior to the trigger of convection near the boundary layer, which extends into the lower troposphere (up to $4 \mathrm{~km}$; Fig. 6, top panel). By contrast, there exist a warm bias of around $0.8 \mathrm{~K}$ in the late afternoon to predawn when the peak in the diurnal cycle of precipitation occurs, although it is mainly confined to the surface layer (below $200 \mathrm{~m}$ ). These biases exhibit a similar diurnal structure as the mean diurnal variation of the observed $\theta$ anomalies (see Fig. 9a of Yokoi et al. 2017), suggesting that they are due to the inability of the model to properly capture this diurnal variation. Yokoi et al. (2017) commented that such a diurnal variation was consistent with the diurnal cycle of insolation. We note that Pre-YMC radiosonde $T$ data near the surface may be influenced by R/V Mirai itself, or even nearby buildings at Bengkulu (K. Yoneyama 2020, personal communication), thus leading to observation biases. However, comparison with 3-hourly surface observations assimilated throughout the SINGV-DA domain yielded a strikingly similar mean diurnal variability in the biases (not shown), suggesting that it is indeed a model issue and may also not be unique to Bengkulu.

Dipankar et al. (2019) noted that the mean buoyancy in observations over Bengkulu was more positive between 1100 and 1500 LT than in the simulations, which could be 

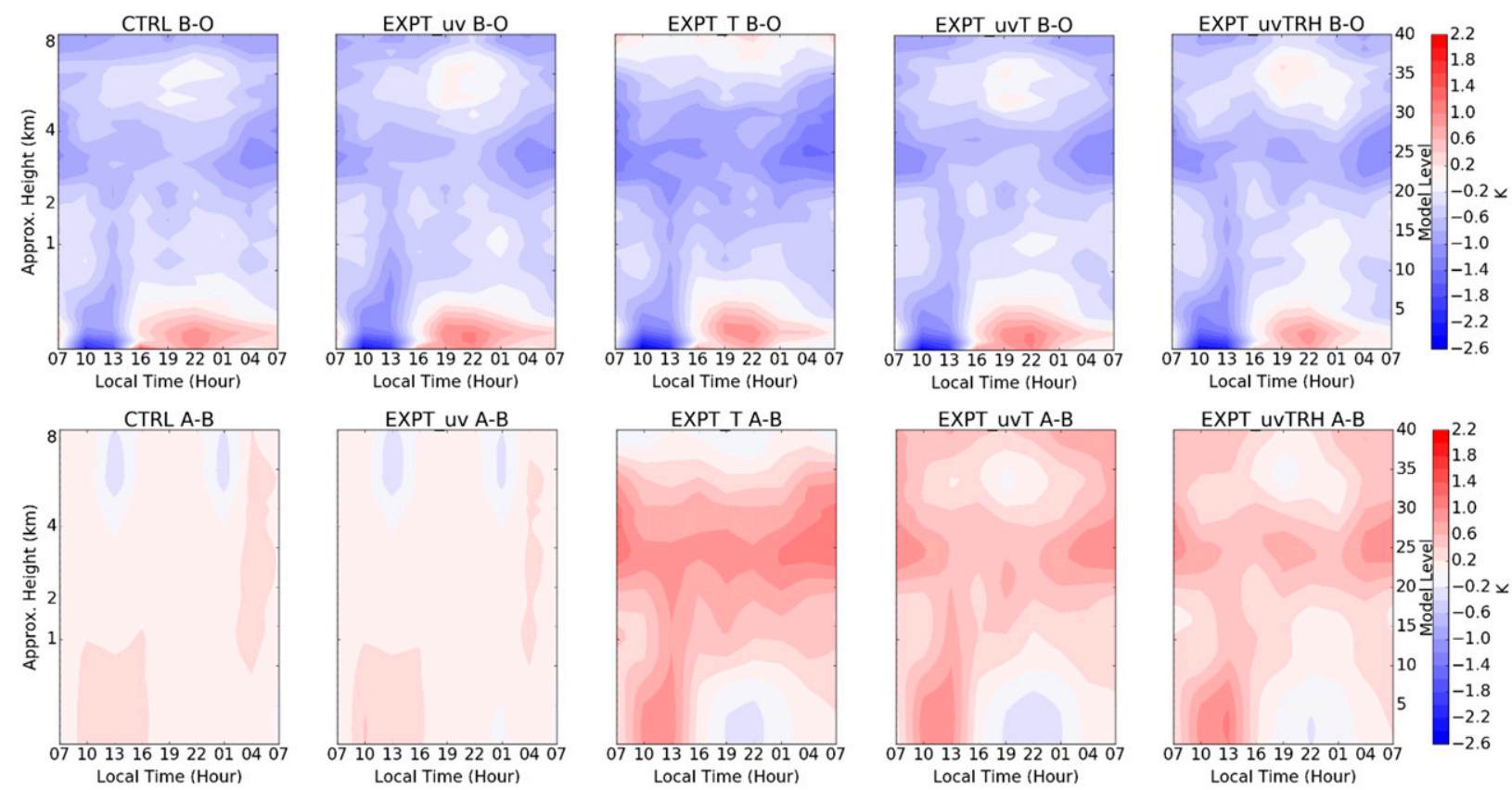

FIG. 6. Mean diurnal variation of (top) background minus observation $(B-O)$ vertical profiles of $\theta$ and (bottom) corresponding mean $\theta$ analysis increments $(A-B)$ at Bengkulu at initialization time for the five VDEs (from left to right): CTRL, EXPT_uv, EXPT_T, EXPT_uvT, and EXPT_uvTRH. Composites of vertical profiles for each VDE are taken according to the initialization time over the 19 days of the simulation period.

related to the $\theta$ biases. They inferred that the trigger of convection was dictated by the convergence of the cold pool from the afternoon rainfall (starts around $1400 \mathrm{LT}$ ) over the adjacent mountains with the prevailing near-surface westerlies (Fig. 2). Thus, one may expect that resolving this cold bias could improve the strength and timing of the sea breeze, which interacts with orography (Mori et al. 2004; Wu et al. 2009) and thus the timing of convection over the mountains. This effect should be closely related with resolving the horizontal wind biases in section 3a. Similarly, resolving this warm bias (from 1600 to 0100 LT) could improve the timing of the cold pool convergence with the prevailing near-surface westerlies and hence the timing of peak convection over Bengkulu, which was previously delayed (Fig. 3).

As before, we assess the $\theta$ analysis increments around Bengkulu. There is little diurnal variation in the $\theta$ analysis increments in CTRL and EXPT_uv below the tropopause, as expected because $T$ is not assimilated from Pre-YMC radiosonde data in both VDEs (Fig. 6, bottom panel); most of the small analysis increments in the lower troposphere are only due to the assimilation of satellite observations. The mean diurnal variation of $\theta$ analysis increments in EXPT_T, EXPT_uvT and EXPT_uvTRH are more substantial, generally opposite of the associated biases. This pattern is reasonable since the analysis increments from the data assimilation attempts to correct the diagnosed biases. Larger positive analysis increments of around $1 \mathrm{~K}$ near the boundary layer, extending throughout the lower troposphere suggest an increase in lower tropospheric instability in the morning to early afternoon prior to the trigger of convection over the adjacent mountains. As discussed above, these analysis increments should improve the strength of the sea breeze. By contrast, during the late afternoon to predawn, the $\theta$ analysis increments are negative and confined to the boundary layer. These analysis increments should reduce the warm bias and possibly advance the onset of the cold pool in the late afternoon.

While it appears that with the additional $T$ information and resulting $\theta$ analysis increments, the initial conditions for the simulations should be better prescribed, they did not necessarily reduce the short-range biases. The diurnal variation of the biases in EXPT_T, EXPT_uvT, and EXPT_uvTRH still appear very similar to CTRL, if not worse. This comparison again suggests that the model tends to adjust back to a state that is inconsistent with observations, possibly related to the persistence of horizontal wind biases in section $3 \mathrm{a}$.

\section{c. 3-h biases and analysis increments in total specific humidity over Bengkulu}

Here, we define total specific humidity as $q_{T}=q_{v}+q_{c}$, where $q_{v}$ is the vapor specific humidity and $q_{c}$ is the cloud liquid and solid water; $q_{T}$ is discussed instead of RH since it is more intuitive to understand if moisture is added or removed. Note that for the RH biases, they have to be converted to $q_{T}$ biases using $q_{T}=q_{v}$ since there is no cloud component deduced from RH. These biases are subsequently compared with the analysis increments of $q_{T}$.

In CTRL, EXPT_uv, EXPT_uvT, and EXPT_uvTRH, there is a clear dry bias of around $0.6-1.6 \mathrm{~g} \mathrm{~kg}^{-1}$ in the lower troposphere (1-4 km) throughout the day (Fig. 7, top panel), 

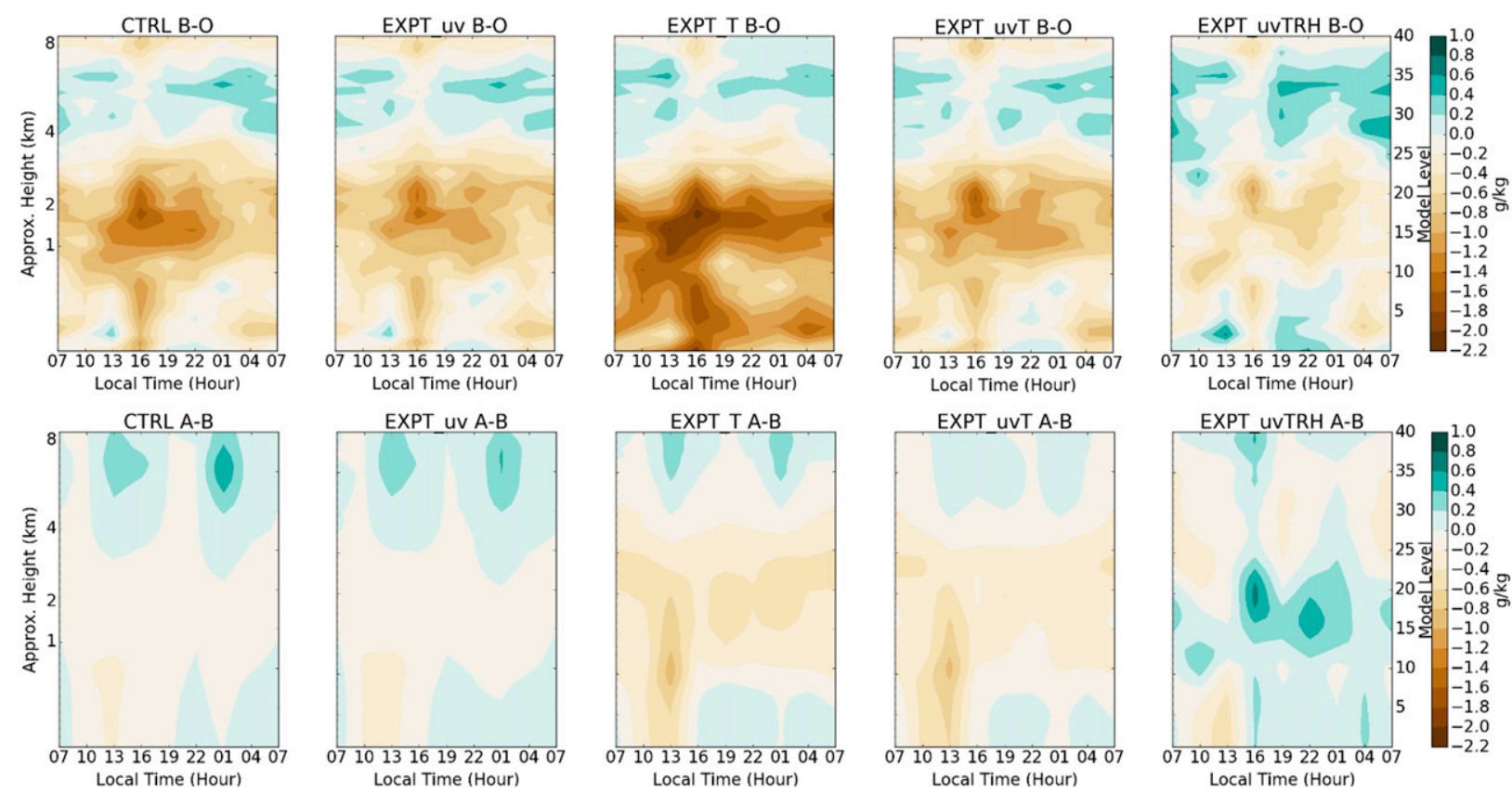

FIG. 7. Mean diurnal variation of (top) background minus observation $(B-O)$ vertical profiles of $q_{T}$ and (bottom) corresponding mean $q_{T}$ analysis increments $(A-B)$ at Bengkulu at initialization time for the five VDEs (from left to right): CTRL, EXPT_uv, EXPT_T, EXPT_uvT, and EXPT_uvTRH. Composites of vertical profiles for each VDE are taken according to the initialization time over the 19 days of the simulation period.

extending to the boundary layer (below $1 \mathrm{~km}$ ) at $1600 \mathrm{LT} 3 \mathrm{~h}$ before the peak in the diurnal cycle of precipitation. During the late afternoon to midnight, there also exists a slight wet bias in the boundary layer, which is more apparent in EXPT_ uvTRH than the rest. More notably, the dry bias in EXPT_T is the worst compared to the other VDEs, ranging from 1 to $2 \mathrm{~g} \mathrm{~kg}^{-1}$ and exhibited at every cycle of the day throughout the lowest $3 \mathrm{~km}$. There is no reason to suspect that the biases in the five VDEs are due to observation biases given that the most reliable sensors were used in the computation of $\mathrm{RH}$ for Pre-YMC radiosonde data (K. Yoneyama 2020, personal communication). The UM-which SINGV-DA uses-can have a dry bias over the Maritime Continent (Neale and Slingo 2003; Love et al. 2011; Dipankar et al. 2019). Neale and Slingo (2003) suggested that the dry bias may be due to deficiencies in the representation of physical processes, which are not related to the model resolution. Additionally, another conflating factor could be the inheritance of these biases from the ECMWF analyses as the initial conditions (Dipankar et al. 2019).

One might hypothesize that the dry biases could be responsible for the weaker diurnal cycle over Bengkulu (Fig. 3). It is reasonable to expect that reducing the dry biases (i.e., increasing the moisture) in the boundary layer and the lower troposphere at $1600 \mathrm{LT}$ - the time when the environment is favorable for convection-would lead to a more intense and perhaps earlier convection. The effect should be closely related to the entrainment of moist air in the convective plume (Tompkins 2001; Derbyshire et al. 2004).

As before, we assess the $q_{T}$ analysis increments around Bengkulu. The multivariate relationships prescribed in modeling the background error covariance matrix for 3D-Var
FGAT, particularly between $\theta$ and $q_{T}$ must be considered when comparing EXPT_T and EXPT_uvTRH with the other three VDEs. We note that the $q_{T}$ background errors are moderately and negatively correlated to the $\theta$ background errors in SINGV-DA when the background is relatively dry ( $\mathrm{RH}$ below $80 \%$ ). This correlation is further discussed in section 5.

In CTRL and EXPT_uv, there is little diurnal variation in the analysis increments in the troposphere (Fig. 7, bottom panel). Any $q_{T}$ analysis increments present are generally opposite of the $\theta$ analysis increments, likely a result of the negative correlation between the $\theta$ and $q_{T}$ background errors. In EXPT_uvTRH, moisture is added in the lower troposphere to correct for the dry bias. However, moisture is added in the late afternoon to midnight instead of being removed near the surface, also a result of the prescribed negative correlation; cooling the boundary layer resulted in the addition of a small amount of moisture. In EXPT_T and EXPT_uvT, the negative correlation plays a critical role in determining the mean diurnal variation of the $q_{T}$ analysis increments. The $q_{T}$ analysis increments are generally opposite of the $\theta$ analysis increments in the boundary layer and lower troposphere, ranging between 0.6 and $1 \mathrm{~g} \mathrm{~kg}^{-1}$. Due to the absence of moisture information being assimilated in EXPT_T and EXPT_uvT, the $q_{T}$ analysis increments are prescribed following the multivariate relationships of the background error constraints, which we believe may not always be physically meaningful over Bengkulu.

In EXPT_T, the effect of solely assimilating $T$ information together with the prescribed negative correlation worsened the dry biases compared to CTRL. We also note that in 

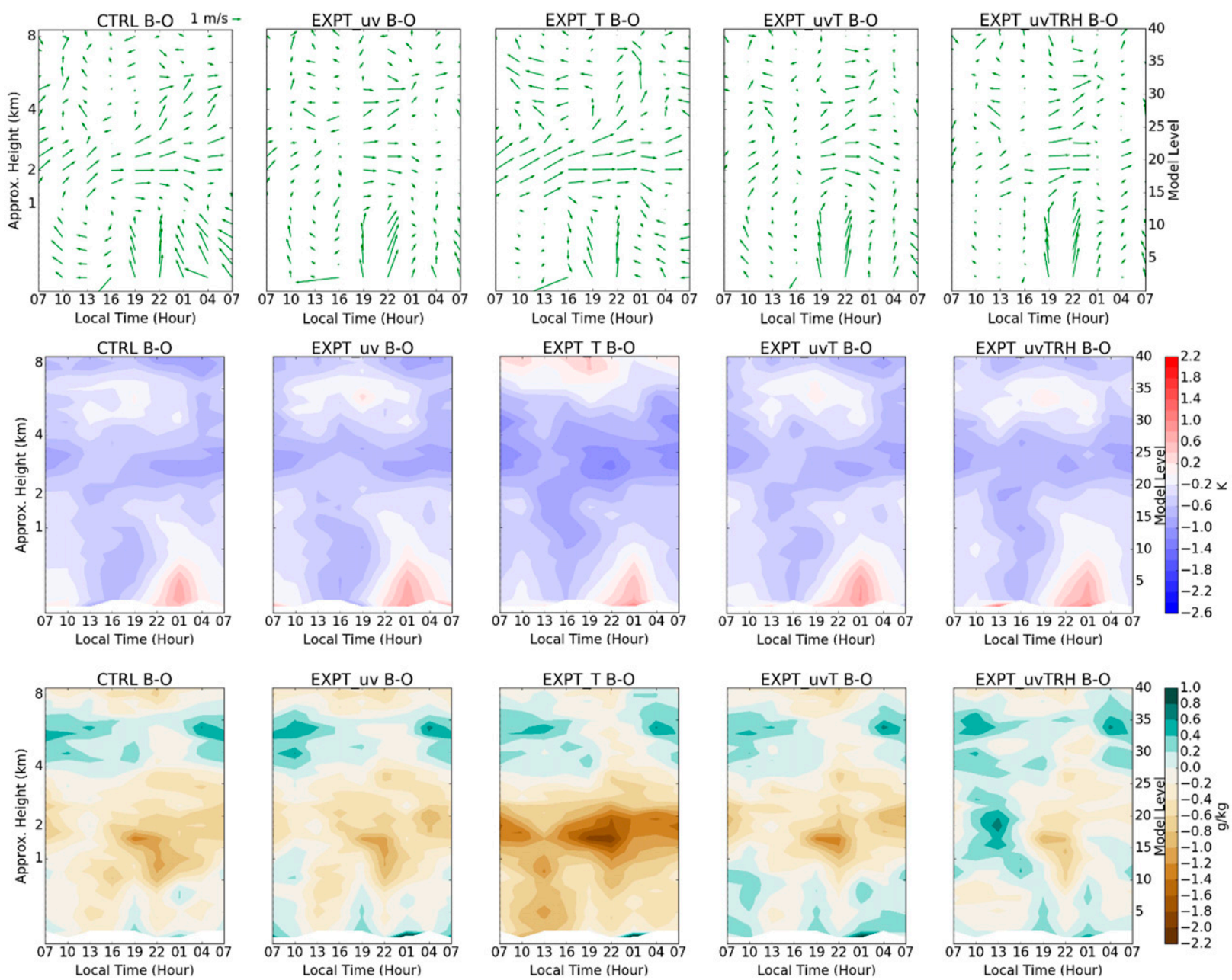

FIG. 8. Mean diurnal variation of background minus observation $(B-O)$ vertical profiles of (top) horizontal wind, (middle) $\theta$, and (bottom) $q_{T}$ at Mirai at initialization time for the five VDEs (from left to right): CTRL, EXPT_uv, EXPT_T, EXPT_uvT, and EXPT_ uvTRH. Composites of vertical profiles for each VDE are taken according to the initialization time over the 19 days of the simulation period.

EXPT_uv and EXPT_uvT, there is a slight reduction in the dry bias (about $0.2 \mathrm{~g} \mathrm{~kg}^{-1}$ ) below $1 \mathrm{~km}$ at $1600 \mathrm{LT}$ compared to CTRL, even without the $q_{T}$ analysis increments. In EXPT uvTRH, the assimilation of moisture information has helped to substantially reduce the dry bias in the lower troposphere, compared to the other three VDEs where $\mathrm{RH}$ was not assimilated. The $q_{T}$ analysis increments generally appear reasonable, suggesting that the additional moisture information might be helpful for better prescribing the initial conditions.

\section{d. 3- $h$ biases over Mirai}

The focus in section 3 is mainly on the biases and increments over Bengkulu since the weaker and delayed convection over Bengkulu can also indirectly affect the subsequent offshore propagation (e.g., through a weaker cold pool formation and propagation). However, the biases over Mirai may still contribute to the hindering of subsequent offshore propagation of precipitation across Mirai (Fig. 4). Following sections 3a-c, the wind, $\theta$, and $q_{T}$ biases over Mirai are computed (Fig. 8).
There exists an approximately onshore wind bias of around $3 \mathrm{~m} \mathrm{~s}^{-1}$ between 1 and $3 \mathrm{~km}$, which persist throughout the day in CTRL and EXPT_T when wind information was not assimilated (Fig. 8, top row). The wind biases are reduced in EXPT_uv, EXPT_uvT, and EXPT_uvTRH, especially during the night and predawn hours, and only persist at 1900 and 2200 LT. This pattern was also previously noted over Bengkulu (section 3a) where there was a strong westerly wind bias over Bengkulu at 1900 and $2200 \mathrm{LT}$, the time when precipitation typically propagates offshore over Bengkulu and Mirai. We speculate that the presence of these biases may be partly hindering the offshore propagation of precipitation.

The structure of the diurnal variation of the $\theta$ biases (Fig. 8 , middle row) between the five VDEs are relatively similar. There exists a warm bias of around $0.6 \mathrm{~K}$ in the boundary layer below $500 \mathrm{~m}$ at 2200-0400 LT, the time when the cold pool typically reaches Mirai. The warm bias may be due to a possible delay in the offshore propagation of the cold pool from Bengkulu to Mirai. This delay may also affect the timing 
of low level convergence with the prevailing westerlies at Mirai.

There also exists a dry bias of around $0.4-1.0 \mathrm{~g} \mathrm{~kg}^{-1}$ in the lower troposphere (between 1 and $4 \mathrm{~km}$; Fig. 8, bottom row) from 1900 to 0700 LT in the five VDEs. The biases are generally larger by around $0.8 \mathrm{~g} \mathrm{~kg}^{-1}$ in EXPT_T, likely due to the multivariate relationships of the background errors as mentioned in section $3 \mathrm{c}$. With the additional moisture information assimilated in EXPT_uvTRH, the magnitude of the dry bias is reduced. It is interesting to note how the dry biases in the lower troposphere are most prominent over Bengkulu and Mirai around $3 \mathrm{~h}$ before precipitation propagates over each station, at 1600 and 1900 LT, respectively. We believe that the dry biases are a major factor which hinders the offshore propagation of precipitation, noting that precipitation propagates across Mirai only in EXPT_uvTRH, but eventually fails to continue to propagate farther offshore (Fig. 4). It is possible that the offshore environmental conditions are generally too dry in the VDEs prior to the time of arrival of the cold pool. While the additional Bengkulu and Mirai radiosondes have provided moisture information (only in EXPT_uvTRH) to reduce the dry biases over each station, they are insufficient to influence the environment farther offshore.

\section{Observed and simulated diurnal cycle of precipitation over Bengkulu}

By comparing the simulated and observed diurnal cycle of precipitation over Bengkulu, one may deduce the relative impacts of assimilating additional radiosonde wind, temperature, and moisture information. The comparison may also provide insights on the value of information of different variables and highlight known issues that may degrade the forecasts.

\section{a. Simulated diurnal cycle compared against satellite-derived precipitation}

Satellite-derived precipitation, albeit with known biases (Vernimmen et al. 2012; Rauniyar et al. 2017), can be useful for performing an initial assessment of the accuracy of simulations in capturing the general spatial distribution of precipitation and its evolution. The simulated precipitation from the five VDEs have been compared with the GPM data created with the Integrated Multisatellite Retrievals for GPM (GPM_3IMERGHHL v06, Huffman et al. 2019), which is available at $0.1^{\circ} \times 0.1^{\circ}$ spatial resolution and 30-min temporal resolution (Fig. 4). The differences between the VDEs are subtle in the Hovmöller diagrams (Fig. 4) and smoothed due to time averaging, so we further evaluate the VDEs quantitatively for individual forecasts without taking the diurnal mean during the simulation period.

Excluding the spinup period in the simulations, there are 19 forecasts available from each of the eight cycle times, yielding a total of 152 forecasts from each VDE for evaluation. Fractions skill score (FSS; Roberts and Lean 2008) statistics are computed from hourly accumulated precipitation of each of the 152 forecasts over the smaller GPM VER domain around Bengkulu and Mirai (Fig. 1b). We expect the assimilation to not only impact the simulated precipitation over Bengkulu, but nearby surrounding areas as well. The FSS are computed using a neighborhood size of $50 \mathrm{~km}$ (five GPM grid lengths), as a function of eight precipitation thresholds $(0.125,0.25,0.5,1,2,4,8$, and $16 \mathrm{~mm})$. Note that we have used the GPM Late Precipitation product, which is calibrated to be more suitable for comparing absolute threshold values. Differences in FSS in relation to CTRL for various forecast lead times are accumulated and shown using Hinton diagrams (Fig. 9) to illustrate the improvement or degradation associated with the assimilation of additional wind, temperature and moisture information compared to CTRL.

For EXPT_uv, the assimilation of only wind information generally led to an improvement of the forecasts compared to CTRL. Larger FSS were computed for almost all forecast lead times (up to $24 \mathrm{~h}$ ) for precipitation thresholds less than $4 \mathrm{~mm}$. Some of the results were also statistically significant, especially for shorter forecast lead times of up to $12 \mathrm{~h}$. The results indicate that it is possible to perform more accurate simulations of precipitation over the region with only corrections to the wind biases. They also demonstrate the importance of wind information over the western coast of Sumatra, which can arguably be applicable to the broader tropics (Žagar et al. 2004a). There appears to be little detrimental effects of only observing wind, at least in SINGV-DA.

For EXPT_T, the assimilation of only $T$ information generally resulted in a degradation of the forecasts compared to CTRL. While the very short-range forecasts (less than 5-h lead time) had significantly larger FSS for precipitation thresholds less than $4 \mathrm{~mm}$, significantly smaller FSS were also present for forecast lead times longer than $5 \mathrm{~h}$. The degradation in the forecasts may be attributed to the worsening of the dry biases and reduced available moisture highlighted previously, which can influence the precipitation over the surrounding region through further model adjustment processes. These results may indicate some underlying limitations of the system and issues during assimilation when only $T$ is observed.

With the assimilation of both wind and $T$ information, the forecasts from EXPT_uvT are generally improved compared to CTRL. The EXPT_uvT Hinton diagram appears to be somewhat an amalgamation of the EXPT_uv and EXPT_T Hinton diagrams. Larger FSS were computed for shorter-range forecasts (less than 12-h lead time) for precipitation thresholds less than $4 \mathrm{~mm}$, with some showing statistical significance. For longer lead times, the results were neutral compared to the weakly positive results for EXPT_uv. The difference is possibly due to the assimilation of $T$, which had the effect of degrading the forecast for longer lead times, although the combined effect of assimilating both wind and $T$ information is probably not so straightforward.

For EXPT_uvTRH, the assimilation of the additional RH information yielded larger FSS across all thresholds and forecast lead times which were statistically significant for thresholds below $4 \mathrm{~mm}$ and for forecast lead times less than $15 \mathrm{~h}$. The FSS are much larger than those from EXPT_uv and EXPT_uvT, which suggests that the additional moisture information had added value and resulted in more accurate simulations over the region. The larger FSS may be associated with the reduction in the dry bias in the lower troposphere over Bengkulu and its effect on the surrounding region. Overall, there was a large 

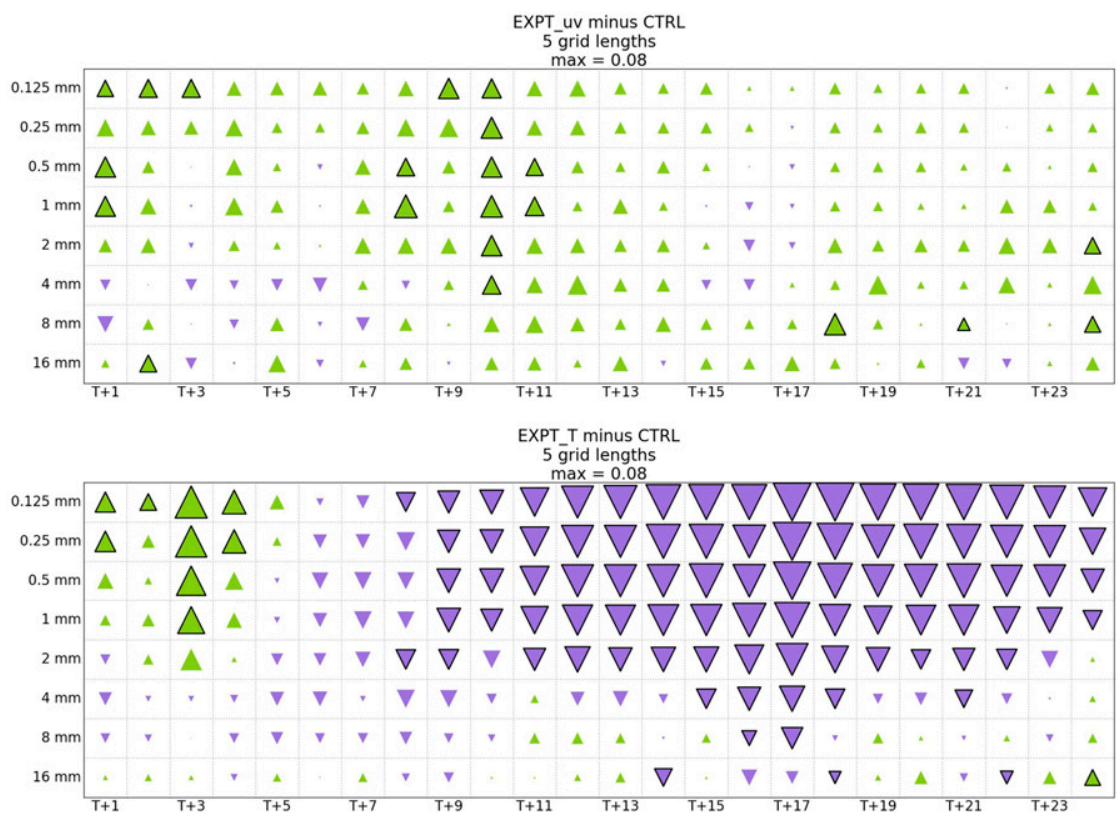

EXPT_uvT minus CTRL 5 grid lengths

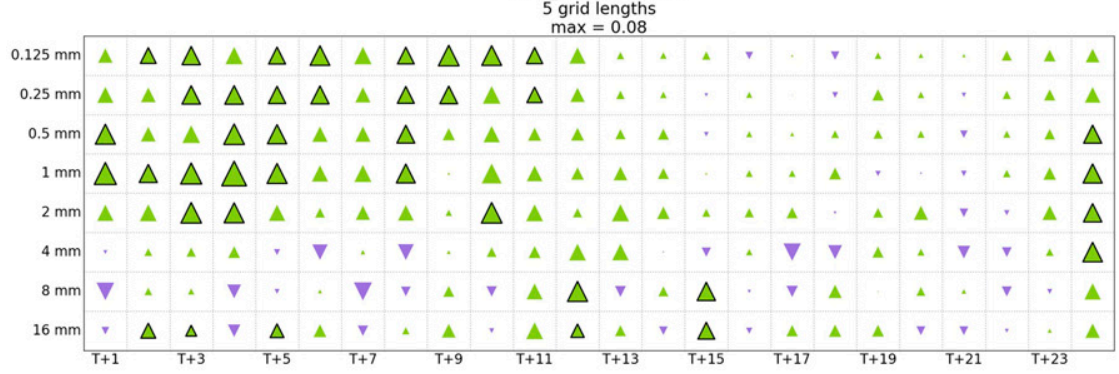

EXPT_uvTRH minus CTRL 5 grid lengths

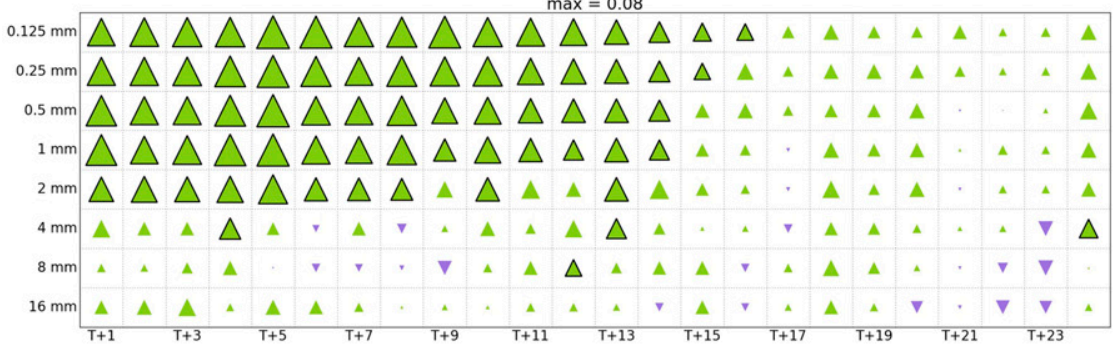

FIG. 9. Hinton diagram showing the FSS for four VDEs compared to CTRL verified using GPM data, computed over the GPM VER domain. See text for details. A green (purple) triangle indicates that the forecasts are improved (degraded). A larger triangle indicates a greater improvement or degradation, by up to 0.08 (the same size as the bounding box). Significance is determined using the nonparametric two-sided Wilcoxon signed-rank test at the $90 \%$ confidence level, indicated using bold triangles.

improvement in the precipitation forecast over the surrounding region.

\section{b. Simulated mean diurnal cycle compared against radar-derived precipitation}

For further verification, we obtain radar-derived precipitation estimates based on reflectivity at an altitude of $2 \mathrm{~km}$ above sea level, interpolated from Mirai radar volume scans. The parameters used in the reflectivity-rainfall relationship are also the same as in Yokoi et al. (2017). This approach would allow for a more rigorous assessment of the accuracy of simulations in capturing the general spatial distribution of precipitation and its evolution near Bengkulu and Mirai. 

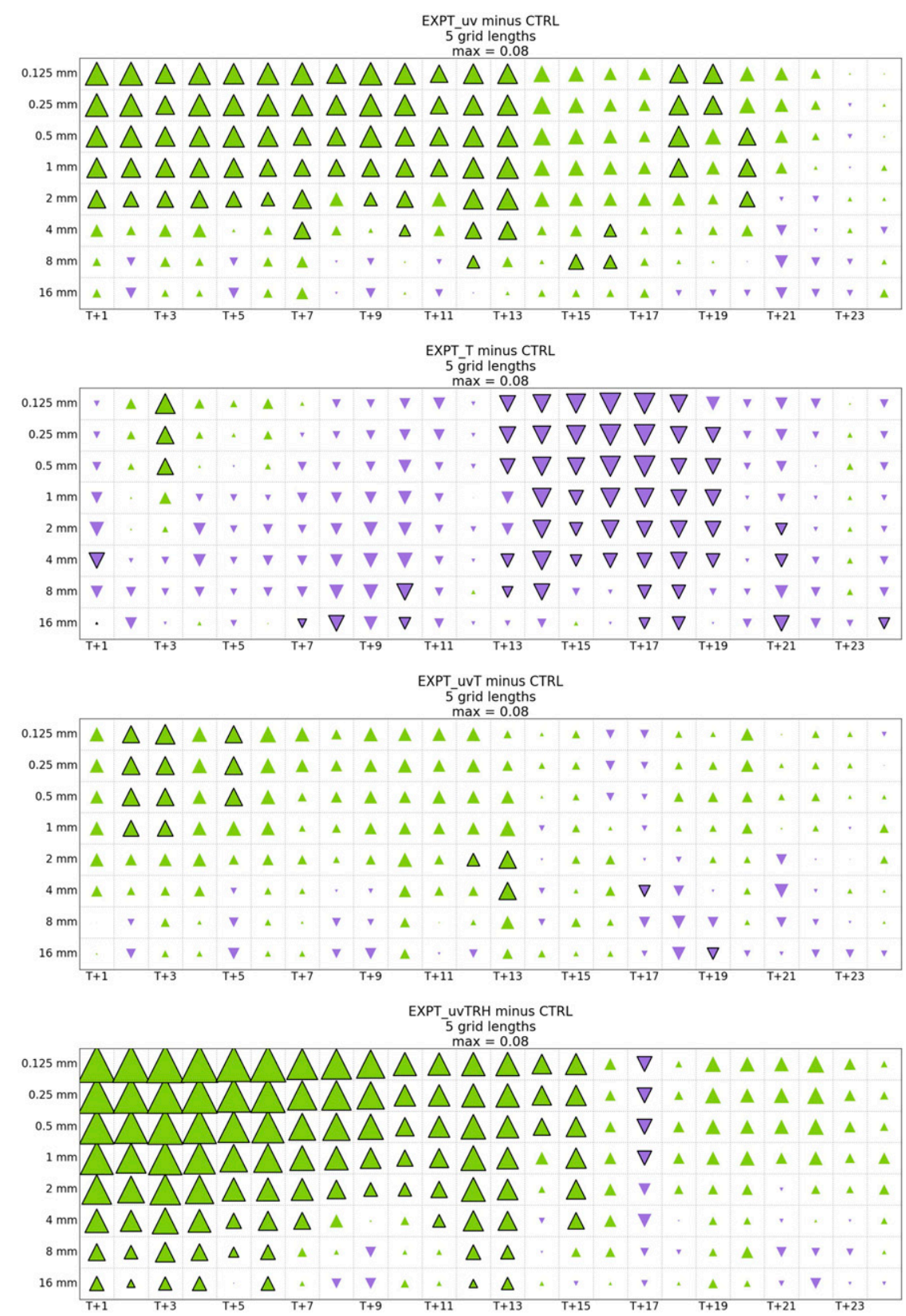

FIG. 10. Hinton diagram showing the FSS for four VDEs compared to CTRL verified using radar-derived precipitation, computed over the RADAR VER domain. See text for details. A green (purple) triangle indicates that the forecasts are improved (degraded). A larger triangle indicates a greater improvement or degradation, by up to 0.08 (the same size as the bounding box). Significance is determined using the nonparametric two-sided Wilcoxon signed-rank test at the $90 \%$ confidence level, indicated using bold triangles.

As in section $4 \mathrm{a}$, there are a total of 152 forecasts from each VDE for evaluation. FSS statistics are computed from hourly accumulated precipitation of each of the 152 forecasts over the RADAR VER domain (Fig. 1b), limited by the range of the Mirai radar. The FSS are computed using a neighborhood size of $5 \mathrm{~km}$ (five interpolated grid lengths), as a function of the same eight precipitation thresholds $(0.125,0.25,0.5,1,2,4,8$, and $16 \mathrm{~mm}$ ). Differences in FSS in relation to CTRL for various forecast lead times are accumulated and shown using Hinton diagrams (Fig. 10).

We note that there are many similarities between Figs. 9 and 10 , even though the forecasts were verified against different observational sources. Similar to Fig. 9, the results from Fig. 10 also indicate that assimilating additional wind information alone 


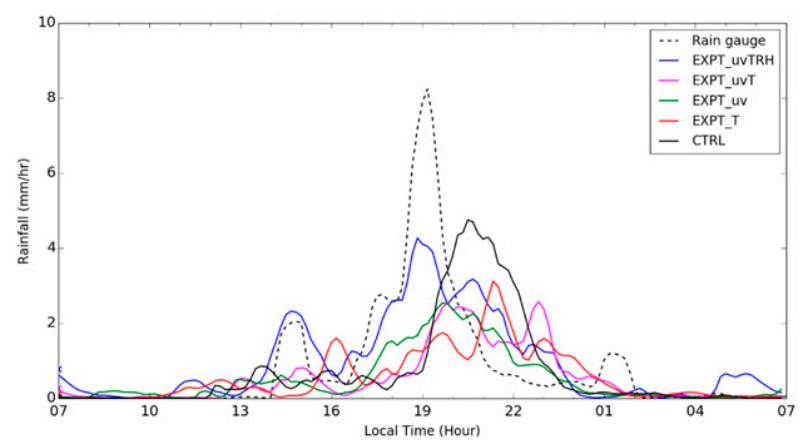

FIG. 11. Mean diurnal cycle of precipitation from the five VDEs compared with rain gauge data from Bengkulu for simulations initialized at $0700 \mathrm{LT}$. The cross indicates the mean 3-h forecast of precipitation from the previous cycle.

was sufficient to improve the forecasts. When assimilating only $T$ information, there was a degradation in the forecasts. Moisture information was also important in improving the accuracy of the simulations over the region. The FSS differences are generally larger in Fig. 10 compared to Fig. 9 because the FSS are accumulated over a smaller domain and better reflects the localized impact of the additional information.

\section{c. Simulated mean diurnal cycle compared against rain gauge}

Apart from assessing the overall changes from all the precipitation forecasts, we also compare the simulations initialized at different cycle times with high frequency rain gauge data over Bengkulu. This approach would provide a more holistic understanding of underlying reasons for any improvement or degradation in the forecasts, which appear particularly pertinent for simulations initialized at certain cycle times.

As part of the Pre-YMC field campaign, continuous surface measurements of precipitation were recorded every minute using a tipping-bucket rain gauge at Bengkulu. To match the 10-min temporal resolution of accumulated rainfall stored from simulations, the rain gauge data has also been accumulated every $10 \mathrm{~min}$ and an hourly running mean has been applied to filter spurious signals, especially since the rain gauge data is based on measurements at a single point. The observed mean diurnal cycle is then computed.

The simulated accumulated rainfall are averaged over a rectangular domain of $20 \mathrm{~km}$ around Bengkulu, to account for slight displacement of any rainfall events and to be consistent with the spatial averaging performed in section 3. Over the simulation period, the 24 -h forecasts are composited according to initialization time (i.e., the mean of all 24-h forecasts initialized at 0700 LT from 24 November to 12 December 2015 is computed to retrieve the mean diurnal cycle of precipitation for $0700 \mathrm{LT}$ ), yielding eight simulated mean diurnal cycle of precipitation from the eight cycle times in a day.

Comparing the simulated and observed mean diurnal cycle of precipitation from rain gauge measurements allows for the phase and amplitude errors to be assessed. The use of the mean diurnal cycle of precipitation is preferred over the full 19-day time series, which can have large discontinuities caused by the
TABLE 2. Statistics comparing the simulated mean diurnal cycle of precipitation of the five VDEs with rain gauge data from Bengkulu. Root-mean-square error and phase lag with respect to the observed diurnal cycle of precipitation are shown for simulations initialized at 0700 and 1300 LT. Note that peak convection typically occurs at 1900 LT over Bengkulu. Values of root-meansquare error and magnitude of phase lag, which are smaller than in CTRL, are indicated in boldface. Values affected by possible spindown issues in the mean diurnal cycle are indicated in italics.

\begin{tabular}{|c|c|c|c|}
\hline $\begin{array}{l}\text { Cycle start time } \\
\text { (time before peak } \\
\text { convection) }\end{array}$ & Abbreviation & $\begin{array}{c}\text { Root- } \\
\text { mean- } \\
\text { square } \\
\text { error } \\
\left(\mathrm{mm} \mathrm{h}^{-1}\right)\end{array}$ & $\begin{array}{l}\text { Phase lag } \\
\text { derived } \\
\text { from time- } \\
\text { lagged cross } \\
\text { correlations } \\
\text { (min) }\end{array}$ \\
\hline \multirow[t]{5}{*}{$0700 \mathrm{LT}(T+12 \mathrm{~h})$} & CTRL & 1.66 & 100 \\
\hline & EXPT_uv & 1.24 & 40 \\
\hline & EXPT_T & 1.50 & 140 \\
\hline & EXPT_uvT & 1.45 & 70 \\
\hline & EXPT_uvTRH & 0.91 & $\mathbf{0}$ \\
\hline \multirow[t]{5}{*}{$1300 \mathrm{LT}(T+6 \mathrm{~h})$} & CTRL & 1.23 & 70 \\
\hline & EXPT_uv & 1.33 & 60 \\
\hline & EXPT_T & 1.27 & 30 \\
\hline & EXPT_uvT & 0.88 & 30 \\
\hline & EXPT_uvTRH & 1.42 & -40 \\
\hline
\end{tabular}

concatenation of 24-h forecasts. In this case, the simulated mean diurnal cycle is often sufficient to represent the simulated typical diurnal cycle for individual days, especially when the diurnal variation is pronounced. As an example, the 1300 LT simulated mean diurnal cycle from EXPT_uvTRH exhibits general features (e.g., early pickup and peak in precipitation) similar to individual simulated diurnal cycles on 25 and 30 November and 1, 3, and 11 December (not shown), which are days when the observed diurnal cycle clearly peaks between 1800 and 2000 LT.

We present two out of the eight simulated mean diurnal cycles: simulations initialized at 0700 LT (Fig. 11) and 1300 LT (Fig. 3). These cycle times may highlight differences associated with the lead time before peak convection over Bengkulu occurs. Additionally, the mean 3-h forecast of precipitation from the previous cycle time is added for reference, indicating if precipitation was already developing over Bengkulu prior to the initialization of the simulations.

We have also computed the root-mean-square errors (RMSE) between the simulated mean diurnal cycle of precipitation and the observed (Table 2), given by

$$
\Delta \mathrm{RMSE}=\sqrt{\frac{\sum_{k=1}^{n}\left(\overline{o_{k}}-\overline{f_{k}}\right)^{2}}{n},}
$$

where $\overline{o_{k}}$ and $\overline{f_{k}}$ is the observed and simulated mean diurnal cycle of precipitation, respectively, and $n=144$, which is the number of 10 -min accumulation periods in $24 \mathrm{~h}$ ( $k$ represents the time index of the 10-min periods).

The computation of RMSE should provide a broad quantitative assessment of the simulations in capturing both the 

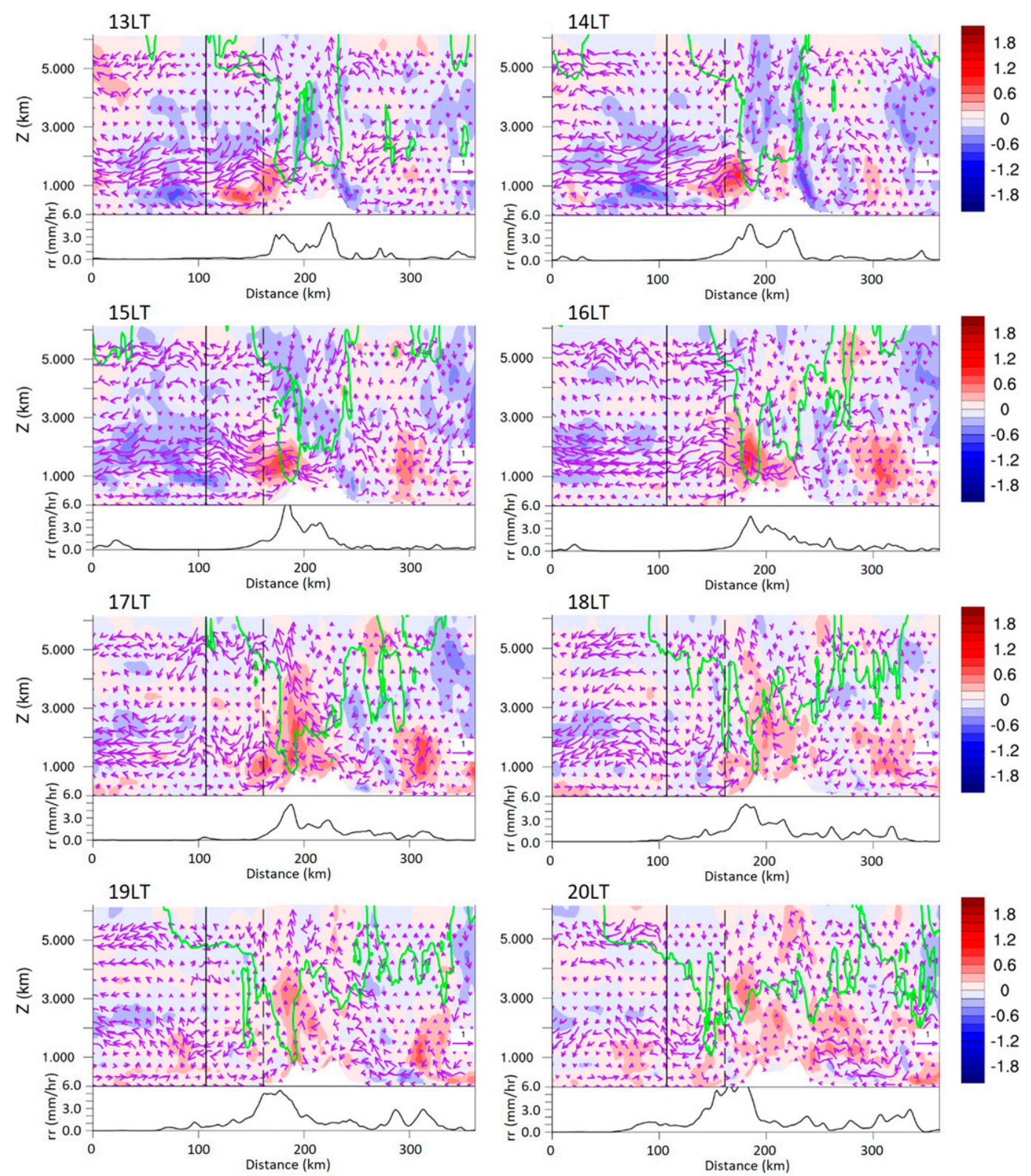

FIG. 12. Transect-height cross sections of the mean vapor specific humidity ( $q_{v}$; shading; units: $\mathrm{g} \mathrm{kg}^{-1}$ ) and wind (quivers; units: $\mathrm{m} \mathrm{s}^{-1}$ ) anomalies in EXPT_uv with respect to CTRL, overlaid on the topography. The evolution of anomalies are shown from the initialization time (1300 LT) up to the 7-h forecast. Cloud locations are enclosed in green. The dashed and solid lines indicate the longitudinal positions of Bengkulu and Mirai, respectively. Rain rate (rr) along the transect is shown at the bottom of each plot. The distance $(\mathrm{km})$ is measured positive from southwest to northeast.

amplitude and phase of the mean diurnal cycle. Furthermore, a phase lag can be derived from the time-lagged cross correlations; defined as the lag $p$ at which $\overline{f_{k}}(p)$ maximizes the Pearson cross correlation with $\overline{o_{k}}$ (Table 2 ). This metric highlights the phase errors of the simulated mean diurnal cycle.

In general, the simulated mean diurnal cycle of precipitation is delayed and weaker in CTRL (Figs. 3 and 11). The phase lag was around $70-140 \mathrm{~min}$ (Table 2) depending on initialization time, and with the simulated peak rainfall around $4 \mathrm{~mm} \mathrm{~h}^{-1}$ lesser than the observed. Similar results were also found in Dipankar et al. (2019) from downscaled simulations.

Given the additional wind information in EXPT_uv, the phase lag has been reduced across both initialization times; the peak convection occurs slightly earlier on average by around 40-50 min compared to CTRL, which is closer to observations. The RMSE of the simulated mean diurnal cycle with respect to the observed is also on average slightly reduced (Table 2), partly due to the reduction in phase lag but also due to the 

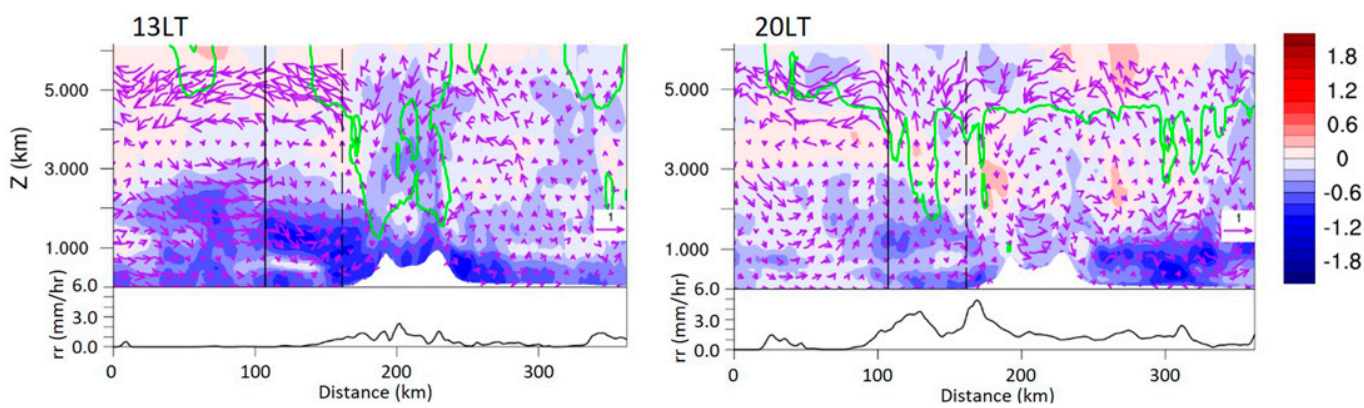

FIG. 13. As in Fig. 12, but for anomalies in EXPT_T with respect to CTRL for the initialization time (1300 LT) and 7-h forecast (2000 LT).

slightly increased amplitude of around $2 \mathrm{~mm} \mathrm{~h}^{-1}$ for simulations initialized $6 \mathrm{~h}$ before (1300 LT; Fig. 3).

The improvements are due to the horizontal wind analysis increments, which is the main difference between EXPT_uv and CTRL. Figure 12 shows the mean $q_{v}$ and wind anomalies with respect to CTRL for the transect-height cross sections (see Fig. 1b) running through Bengkulu and Mirai. We note that the sea breeze is enhanced at initialization time (1300 LT) compared to CTRL, which persist up to $1600 \mathrm{LT}$. There is also a larger moisture buildup (positive $q_{v}$ anomalies) compared to CTRL over Bengkulu, triggering stronger convection over the mountains. We hypothesize that the enhanced sea breeze has advected additional moisture from farther offshore which better conditions the environment to be favorable for convection at 1400 LT. Additionally, there exist offshore wind anomalies compared to CTRL between 1 and $2 \mathrm{~km}$ at initialization time, which we believe could improve the offshore propagation of precipitation. Correspondingly, the precipitation peaks at Bengkulu about $1 \mathrm{~h}$ earlier than in CTRL at $2000 \mathrm{LT}$.

Given the additional $T$ information in EXPT_T, the phase lag has been slightly reduced by around $40 \mathrm{~min}$ compared to CTRL for the simulations initialized just prior to peak convection at $1300 \mathrm{LT}$. The phase lag is worse for simulations initialized at 0700 LT (Fig. 11), when there is a longer forecast lead time before peak convection. In general, the simulated peak rainfall was also around $2 \mathrm{~mm} \mathrm{~h}^{-1}$ lesser than in CTRL, leading to a slightly larger RMSE for simulations initialized at 1300 LT. We believe that the smaller amplitude is due to the worsening of the dry bias and reduced available moisture (section $3 \mathrm{c}$ ) throughout the lower troposphere compared to CTRL. There exist negative $q_{v}$ anomalies below $3 \mathrm{~km}$ (Fig. 13), which persist for more than $7 \mathrm{~h}$ (shown only for 1300 and 2000 LT) after initialization time, reducing the equivalent $\theta$ below $3 \mathrm{~km}$ (not shown) and hence increasing the environmental stability over Bengkulu and adjacent mountains. Consequently, there is anomalous descent (weaker ascent) in EXPT_T over the adjacent mountains at initialization time, resulting in a slightly weaker convection compared to CTRL.

In EXPT_uvT, the combination of both the additional wind and $T$ information resulted in a mean diurnal cycle which exhibits features from both EXPT_T and EXPT_uv. For simulations initialized after peak rainfall, the simulated peak rainfall appears to be reduced compared to CTRL, which is likely related to the removal of moisture in the lower troposphere caused by the assimilation of $T$. However, there is also an improvement in the phase of the diurnal cycle; the phase lag is reduced by around 40 min compared to CTRL, which may in part be caused by the assimilation of wind information as highlighted earlier.

In EXPT_uvTRH, the assimilation of the additional RH information resulted in some peculiar features in the simulations. For the simulations initialized at 1300 LT (Fig. 3), there is a sharp pickup in precipitation shortly after initialization, leading to RMSE values which are larger compared to CTRL. Such issues with the sudden pickup in precipitation have been reported in previous studies (Ingleby et al. 2013; Schwartz and Liu 2014), often termed as spindown because the precipitation amount is higher than it ought to be and slowly relaxes to a lower value. The spindown issue usually occurs because of an initialization imbalance but may also be related to other known issues in assimilating atmospheric water-related observations (Bannister et al. 2020), since it is not clearly evident in other VDEs. This issue is further discussed in section $5 \mathrm{~b}$. Nevertheless, we note that for the simulations initialized at $0700 \mathrm{LT}$, the simulated mean diurnal cycle is greatly improved compared to CTRL, as seen in the reduction of RMSE and phase lag.

\section{Limitations of the system}

\section{a. Background error correlations and choice of moisture control variable}

As noted in section $3 \mathrm{c}$, the multivariate relationships prescribed in modeling the background error covariance matrix for 3D-Var FGAT need to be considered. These relationships can constrain the analysis increments and determine the spreading of information between variables (Bannister 2008a,b). Depending on the constraints, they can contaminate the analyses instead of spreading information between variables meaningfully, resulting in a suboptimal estimate of the initial conditions.

The background error covariance matrix is often modeled from a set of training data that is assumed to represent the climatological background error statistics. For SINGV-DA, the lagged National Meteorological Center method (Parrish and Derber 1992) is employed (see Heng et al. 2020). A so-called control variable transform (Bannister 2008b) is usually applied, which determines the multivariate relationships depending on the choice of control variables and relationships (such as statistical 

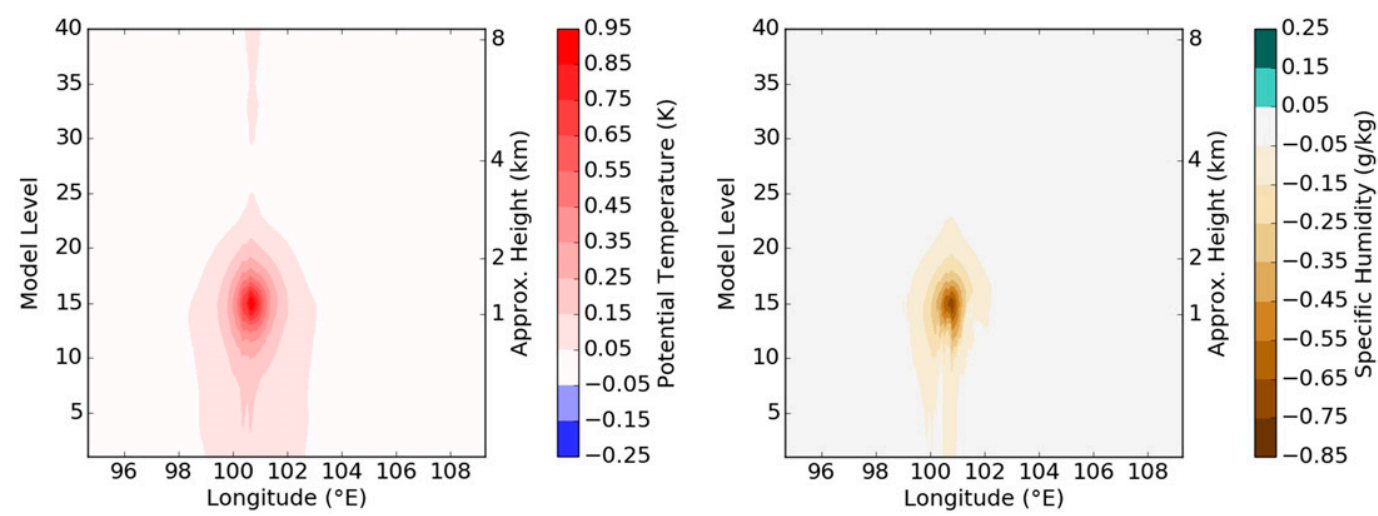

FIG. 14. Longitude-height cross section of the analysis increments of (left) $\theta$ and (right) $q_{T}$ as a result of assimilating a pseudo-single observation of $\theta$. See text for details on pseudo-single observation.

linear regression or analytical balance operators) between them. These multivariate relationships can be extracted by inserting a single observation of a specific variable and assessing the resulting analysis increments from all other variables. To illustrate, a pseudo-single observation of $\theta$, which is $1 \mathrm{~K}$ above the background is inserted at around $1 \mathrm{~km}$ altitude near the center of the domain (Fig. 1a) with an observation error of $0.2 \mathrm{~K}$.

We focus on the prescribed relationship between $\theta$ and $q_{T}$ background errors since they have been shown to influence the analysis increments in the VDEs (section 3c). A longitudeheight cross section (up to $8 \mathrm{~km}$ ) is taken across the inserted $\theta$ observation to show the resulting $\theta$ and $q_{T}$ analysis increments (Fig. 14) even though no information on $q_{T}$ is assimilated. This result demonstrates that the $q_{T}$ background errors are moderately and negatively correlated to the $\theta$ background errors in SINGV-DA. Note that we are using the nonlinear moisture control variable of Ingleby et al. (2013), so the correlation depends on the background $\mathrm{RH}$ and model level. Based on the calibrated data, a negative correlation is prescribed when the background is relatively far from saturation ( $\mathrm{RH}$ below $80 \%$ ) for observations in the lower troposphere. A positive correlation between the $\theta$ background errors and $q_{T}$ background errors is only present if the background $\mathrm{RH}$ is above $80 \%$ for observations in the boundary layer and near $100 \%$ for observations in the upper troposphere, which would essentially result in approximately uncorrelated $\theta$ and $\mathrm{RH}$ background errors. Lorenc (2007) discusses how the neglect of correlations between RH and temperature-related errors are not usually justified, such as in regions where the vertical motion is incorrect. In a convective scenario, it may also not be physically reasonable to remove moisture with a positive $\theta$ increment, where perhaps there should not exist any correlation between the $\theta$ and $q_{T}$ background errors. Such issues are not unique to SINGV-DA, and has been discussed in previous studies (Lorenc et al. 1996; Dee and Da Silva 2003).

From sections 3 and 4, it appears that the negative correlation did appear to cause unphysical behavior when moisture information was not assimilated, which degraded the estimates of the initial conditions and thus the simulations.

Perhaps it is also important to consider other multivariate relationships (e.g., mass-wind) and their impact on the system.
However, these did not appear to have substantial influence on the mean diurnal variation of the analysis increments. Particularly for zonal wind and mass variables, a weak positive correlation is typically present at the point of observation, which depends on the calibration statistics from the set of training data. Further discussion on such relationships in the tropics is provided in Lee and Huang (2020).

Given the complications and limitations involved in the specification of the background error constraints and choice of control variables based on climatological statistics, it might be more productive to focus future efforts on deriving suitable ensemble-based background error statistics (e.g., Evensen 1994; Lorenc 2003; Buehner 2005) for limited-area models, such as in Montmerle et al. (2018) and Caron et al. (2019). The approach uses multivariate relationships prescribed directly between variables and should be worth testing over the western coast of Sumatra.

\section{b. Initialization and assimilation of moisture}

Even though the moisture analysis increments appear relatively reasonable, they may create imbalances in the initial conditions which can result in spindown issues (Bannister et al. 2020). Analysis increments in other variables may also influence the initialization imbalances. SINGV-DA currently introduces the analysis increments uniformly over a fixed 2-h window centered on analysis time using a method called Incremental Analysis Update (IAU; Bloom et al. 1996) which should reduce the shock to the system when observations are assimilated. However, as shown in Fig. 3, it did not always prevent the spindown issue from occurring. Figure 15 shows how the excess moisture in EXPT_uvTRH resulted in anomalous ascent and precipitation over Bengkulu starting from the initialization time, lasting for the next few hours of the simulations. This pickup in precipitation is early compared to rain gauge observations (Fig. 3). Such spindown issues were also seen in the mean diurnal cycle of precipitation over Bengkulu initialized at $0100 \mathrm{LT}$ (not shown), when strong convection was simulated during the predawn hours, which is absent in the rain gauge observations.

We hypothesize that the early pickup in precipitation could be exacerbated by the readily convective environment with an 

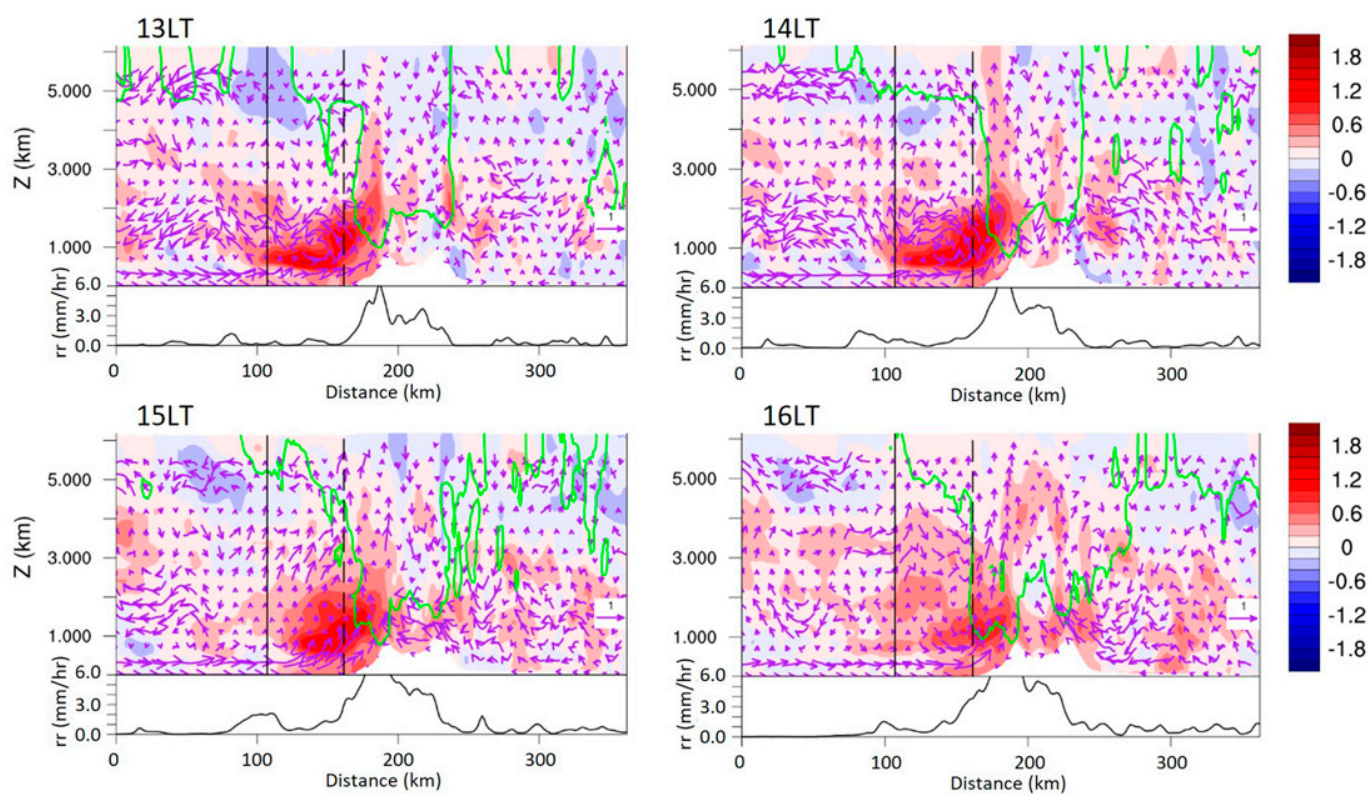

FIG. 15. As in Fig. 12, but for anomalies in EXPT_uvTRH with respect to CTRL for the initialization time (1300 LT) up to the 4-h forecast.

abundance of moisture over the western coast of Sumatra. A continuous addition of $q_{T}$ between 1 and $2 \mathrm{~km}$ due to the assimilation of moisture information could lead to the column water vapor exceeding some critical threshold (Holloway and Neelin 2009), resulting in latent heat release from the condensation of excessive vapor and thus enhanced wind convergence. Therefore, even though the amplitude of the diurnal cycle of precipitation and dry bias can be improved by the addition of moisture, other unintended side effects can occur if the background is already convectively active.

As part of the IAU, a moisture incrementing operator may be used to partition the $q_{T}$ analysis increments into vapor, liquid and frozen cloud water analysis increments. A possible scheme to perform this is described in Sharpe (2007). In SINGV-DA, this technique is bypassed entirely and all $q_{T}$ analysis increments are assigned as $q_{v}$ analysis increments and no attempt is made to modify cloud fractions. Any excess $q_{v}$ is truncated to the saturation limit. The same bypass is performed in UKV, which is a limited-area configuration of the UM centered on the United Kingdom, although future work may involve the application of a new linear moisture incrementing operator (Migliorini et al. 2018) to partition the $q_{T}$ analysis increments (Milan et al. 2020). It would be interesting to also test the new linear moisture incrementing operator for this region. It is possible that the partitioning of $q_{T}$ analysis increments may reduce the latent heat release from the condensation of excessive vapor and reduce the propensity for intense convection occurring after initialization.

Another important aspect of data assimilation involves the assumption of random, unbiased background errors. Given the systematic features in the diurnal variation of $B-O$ statistics and analysis increments seen in section 3 , this assumption is unlikely to be valid. The implications of these biases are not straightforward, but can result in larger analysis increments than optimal and degrade the analyses and thus the forecasts. Dee (2005) describes extensively some bias-aware data assimilation methods that can address such issues, but are not trivial to apply without knowing the source of the biases. These methods could be explored in future data assimilation studies over this region.

\section{Conclusions}

In this article, we assimilated high frequency (3-hourly) radiosonde data from the Pre-YMC campaign over the western coast of Sumatra, in addition to existing available observations. A series of five VDEs were performed to investigate the relative impacts of assimilating additional radiosonde wind, temperature and moisture information on the simulated diurnal cycle of precipitation over Bengkulu, as well as highlight any deficiencies that may occur as a result of the known limitations of the system.

A diagnosis and comparison of the short-range model biases between VDEs using radiosonde data highlighted the presence of wind, temperature and moisture-related biases over Bengkulu. These biases were likely responsible for the delayed and weaker simulated mean diurnal cycle of precipitation over Bengkulu compared to rain gauge observations, when Pre-YMC radiosonde data was not assimilated. While the corresponding analysis increments prescribed through the data assimilation were reasonable when wind and temperature information was assimilated, they did not necessarily reduce the wind and temperature-related biases, suggesting that the model often relaxes to a state that is inconsistent with observations. By contrast, the moisture-related biases were moderately reduced when moisture information was assimilated. We also highlighted how a weaker and delayed 
convection over Bengkulu may subsequently influence the biases over Mirai, and thus farther offshore propagation of precipitation.

The relative impact of assimilating wind, temperature and moisture information on the simulated mean diurnal cycle of precipitation over Bengkulu and the surrounding region was assessed by verifying against satellite-derived precipitation, radar-derived precipitation and rain gauge observations. Even with only wind information assimilated, there were clear improvements in both the phase and amplitude of the simulated mean diurnal cycle over Bengkulu. The verification scores against satellite-derived and radar-derived precipitation in the surrounding region were also significantly higher. The results are likely due to the better representation of the sea breeze and offshore propagation of precipitation shortly after initialization, highlighting the value of wind information in this region, and arguably in the broader tropics.

When only temperature information was assimilated, the phase of the simulated mean diurnal cycle of precipitation over Bengkulu was improved, but only for simulations initialized just prior to peak convection. The amplitude of the simulated mean diurnal cycle was further reduced, due to the prescribed temperature-moisture coupling in the background errors which led to a drying of the lower troposphere that worsened the moisture-related biases. Consequently, there was a significant degradation in the longer-range forecasts, demonstrating the limitations of using climatological background error statistics and the choice of control variables.

The combined impact of assimilating both wind and temperature information appeared to exhibit features from the VDEs assimilating either variable alone. The phase and amplitude of the simulated mean diurnal cycle of precipitation over Bengkulu were generally improved. The verification scores against satellitederived and radar-derived precipitation in the surrounding region were also higher, especially for shorter lead times, but appeared more neutral for longer lead times.

When all variables were assimilated (wind, temperature and moisture), there were significantly higher verification scores in the surrounding region. The amplitude of the simulated mean diurnal cycle over Bengkulu was also greatly improved due to the reduction in dry biases and increased availability of tropospheric moisture. However, there existed a so-called spindown issue occurring for some of the simulations, characterized by a sharp pick-up in precipitation shortly after initialization. This issue highlighted other limitations related to the handling of imbalance in the initialization, as well as moisture addition in an ad hoc manner. Nevertheless, there was an overall positive impact on the forecasts compared to when only wind and temperature were assimilated, suggesting that moisture information is also vital in this region, probably because convection is highly sensitive to the spatial distribution of moisture.

Above all, the VDEs demonstrate that such additional in situ observations are valuable in a data-sparse region such as over the western coast of Sumatra and the broader tropics. There exist great potential for forecast improvements in the region with more high frequency observations, particularly of wind and moisture. Future work should be focused on addressing some of the known issues which can result in assimilation suboptimalities, particularly those related to moisture.
Acknowledgments. We are grateful for fruitful discussions with Ross Bannister and Javier Amezcua. We appreciate the support provided by Met Office staff in this partnership; in particular, Adam Maycock, Adam Clayton, Stefano Migliorini, and Andrew Lorenc. We also thank our colleagues Erik Becker for radar processing scripts, Jerry Liu for inputs on technical issues, and Dale Barker for suggestions to improve the manuscript. The authors declare no potential conflict of interests.

\section{REFERENCES}

Bai, H., and Coauthors, 2021: Formation of nocturnal offshore rainfall near the west coast of Sumatra: Land breeze or gravity wave? Mon. Wea. Rev., 149, 715-731, https://doi.org/10.1175/ MWR-D-20-0179.1.

Bannister, R. N., 2008a: A review of forecast error covariance statistics in atmospheric variational data assimilation. I: Characteristics and measurements of forecast error covariances. Quart. J. Roy. Meteor. Soc., 134, 1951-1970, https://doi.org/10.1002/qj.339.

- 2008b: A review of forecast error covariance statistics in atmospheric variational data assimilation. II: Modelling the forecast error covariance statistics. Quart. J. Roy. Meteor. Soc., 134, 1971-1996, https://doi.org/10.1002/qj.340.

_ H. G. Chipilski, and O. Martinez-Alvarado, 2020: Techniques and challenges in the assimilation of atmospheric water observations for numerical weather prediction towards convective scales. Quart. J. Roy. Meteor. Soc., 146, 1-48, https:// doi.org/10.1002/qj.3652.

Bhatt, B. C., S. Sobolowski, and A. Higuchi, 2016: Simulation of diurnal rainfall variability over the Maritime Continent with a high-resolution regional climate model. J. Meteor. Soc. Japan, 94A, 89-103, https://doi.org/10.2151/jmsj.2015-052.

Birch, C. E., M. J. Roberts, L. Garcia-Carreras, D. Ackerley, M. J. Reeder, A. P. Lock, and R. Schiemann, 2015: Sea-breeze dynamics and convection initiation: The influence of convective parameterization in weather and climate model biases. J. Climate, 28, 8093-8108, https://doi.org/10.1175/JCLI-D-14-00850.1.

Bloom, S. C., L. L. Takacs, A. M. Da Silva, and D. Ledvina, 1996: Data assimilation using incremental analysis updates. Mon. Wea. Rev., 124, 1256-1271, https://doi.org/10.1175/1520-0493(1996) 124<1256:DAUIAU > 2.0.CO;2.

Buehner, M., 2005: Ensemble-derived stationary and flow-dependent background-error covariances: Evaluation in a quasi-operational NWP setting. Quart. J. Roy. Meteor. Soc., 131, 1013-1043, https:// doi.org/10.1256/qj.04.15.

Caron, J. F., Y. Michel, T. Montmerle, and É. Arbogast, 2019: Improving background error covariances in a 3D ensemblevariational data assimilation system for regional NWP. Mon. Wea. Rev., 147, 135-151, https://doi.org/10.1175/MWR-D-180248.1.

Coppin, D., and G. Bellon, 2019: Physical mechanisms controlling the offshore propagation of convection in the tropics: 2 . Influence of topography. J. Adv. Model. Earth Syst., 11, 32513264, https://doi.org/10.1029/2019MS001794.

Dee, D. P., 2005: Bias and data assimilation. Quart. J. Roy. Meteor. Soc., 131, 3323-3343, https://doi.org/10.1256/qj.05.137.

_- and A. M. Da Silva, 2003: The choice of variable for atmospheric moisture analysis. Mon. Wea. Rev., 131, 155-171, https://doi.org/10.1175/1520-0493(2003)131<0155: TCOVFA $>2.0 . \mathrm{CO} ; 2$.

Derbyshire, S. H., I. Beau, P. Bechtold, J. Y. Grandpeix, J. M. Piriou, J. L. Redelsperger, and P. M. M. Soares, 2004: 
Sensitivity of moist convection to environmental humidity. Quart. J. Roy. Meteor. Soc., 130, 3055-3079, https://doi.org/ 10.1256/qj.03.130.

Dipankar, A., S. Webster, X. Y. Huang, and V. Q. Doan, 2019: Understanding biases in simulating the diurnal cycle of convection over the western coast of Sumatra: Comparison with pre-YMC observation campaign. Mon. Wea. Rev., 147, 16151631, https://doi.org/10.1175/MWR-D-18-0432.1.

—_, and Coauthors, 2020: SINGV: A convective-scale weather forecast model for Singapore. Quart. J. Roy. Meteor. Soc., 146, 4131-4146, https://doi.org/10.1002/qj.3895.

Evensen, G., 1994: Sequential data assimilation with a nonlinear quasi-geostrophic model using Monte Carlo methods to forecast error statistics. J. Geophys. Res., 99, 10143-10162, https://doi.org/10.1029/94JC00572.

Faccani, C., and Coauthors, 2009: The impacts of AMMA radiosonde data on the French global assimilation and forecast system. Wea. Forecasting, 24, 1268-1286, https://doi.org/10.1175/ 2009WAF2222237.1.

Gianotti, R. L., D. Zhang, and E. A. Eltahir, 2012: Assessment of the regional climate model version 3 over the maritime continent using different cumulus parameterization and land surface schemes. J. Climate, 25, 638-656, https://doi.org/ 10.1175/JCLI-D-11-00025.1.

Hassim, M. E. E., T. P. Lane, and W. W. Grabowski, 2016: The diurnal cycle of rainfall over New Guinea in convectionpermitting WRF simulations. Atmos. Chem. Phys., 16, 161175, https://doi.org/10.5194/acp-16-161-2016.

Heng, B. C. P., and Coauthors, 2020: SINGV-DA: A data assimilation system for convective-scale numerical weather prediction over Singapore. Quart. J. Roy. Meteor. Soc., 146, 1923-1938, https://doi.org/10.1002/qj.3774.

Holloway, C. E., and J. D. Neelin, 2009: Moisture vertical structure, column water vapor, and tropical deep convection. J. Atmos. Sci., 66, 1665-1683, https://doi.org/10.1175/ 2008JAS2806.1.

Huang, X.-Y., and Coauthors, 2019: SINGV-The convectivescale numerical weather prediction system for Singapore. ASEAN J. Sci. Technol. Dev., 36, 81-90, https://doi.org/ 10.29037/ajstd.581.

Huffman, G., E. F. Stocker, D. T. Bolvin, E. J. Nelkin, and J. Tan, 2019: GPM IMERG final precipitation L3 half hourly 0.1 degree $\times 0.1$ degree V06. Goddard Earth Sciences Data and Information Services Center (GES DISC), accessed 27 December 2019, https://doi.org/10.5067/GPM/IMERG/3B-HH/06.

Im, E. S., and E. A. Eltahir, 2018: Simulation of the diurnal variation of rainfall over the western Maritime Continent using a regional climate model. Climate Dyn., 51, 73-88, https:// doi.org/10.1007/s00382-017-3907-3.

Ingleby, N. B., A. C. Lorenc, K. Ngan, F. Rawlins, and D. R. Jackson, 2013: Improved variational analyses using a nonlinear humidity control variable. Quart. J. Roy. Meteor. Soc., 139, 1875-1887, https://doi.org/10.1002/qj.2073.

Lee, J. C. K., and X. Y. Huang, 2020: Background error statistics in the tropics: Structures and impact in a convective-scale numerical weather prediction system. Quart. J. Roy. Meteor. Soc., 146, 2154-2173, https://doi.org/10.1002/qj.3785.

Lorenc, A. C., 2003: The potential of the ensemble Kalman filter for NWP-A comparison with 4D-Var. Quart. J. Roy. Meteor. Soc., 129, 3183-3203, https://doi.org/10.1256/qj.02.132.

_ 2007: A study of o-b monitoring statistics from radiosondes, composited for low-level cloud layers. Forecasting Research Tech. Rep. 504, 32 pp., http://www.metoffice.gov.uk/.
—, D. Barker, R. S. Bell, B. Macpherson, and A. J. Maycock, 1996: On the use of radiosonde humidity observations in midlatitude NWP. Meteor. Atmos. Phys., 60, 3-17, https://doi.org/ 10.1007/BF01029782.

Love, B. S., A. J. Matthews, and G. M. Lister, 2011: The diurnal cycle of precipitation over the Maritime Continent in a highresolution atmospheric model. Quart. J. Roy. Meteor. Soc., 137, 934-947, https://doi.org/10.1002/qj.809.

Migliorini, S., A. C. Lorenc, and W. Bell, 2018: A moistureincrementing operator for the assimilation of humidity-and cloud-sensitive observations: Formulation and preliminary results. Quart. J. Roy. Meteor. Soc., 144, 443-457, https:// doi.org/10.1002/qj.3216.

Milan, M., and Coauthors, 2020: Hourly 4D-Var in the Met Office UKV operational forecast model. Quart. J. Roy. Meteor. Soc., 146, 1281-1301, https://doi.org/10.1002/qj.3737.

Montmerle, T., Y. Michel, E. Arbogast, B. Ménétrier, and P. Brousseau, 2018: A 3D ensemble variational data assimilation scheme for the limited-area AROME model: Formulation and preliminary results. Quart. J. Roy. Meteor. Soc., 144, 2196-2215, https://doi.org/ 10.1002/qj.3334.

Mori, S., and Coauthors, 2004: Diurnal land-sea rainfall peak migration over Sumatera Island, Indonesian Maritime Continent, observed by TRMM satellite and intensive rawinsonde soundings. Mon. Wea. Rev., 132, 2021-2039, https://doi.org/10.1175/ 1520-0493(2004)132<2021:DLRPMO > 2.0.CO;2.

Neale, R., and J. Slingo, 2003: The Maritime Continent and its role in the global climate: A GCM study. J. Climate, 16, 834-848, https:// doi.org/10.1175/1520-0442(2003)016<0834:TMCAIR >2.0.CO;2.

Ohsawa, T., H. Ueda, T. Hayashi, A. Watanabe, and J. Matsumoto, 2001: Diurnal variations of convective activity and rainfall in tropical Asia. J. Meteor. Soc. Japan, 79, 333-352, https:// doi.org/10.2151/jmsj.79.333.

Parrish, D. F., and J. C. Derber, 1992: The National Meteorological Center's spectral statistical-interpolation analysis system. Mon. Wea. Rev., 120, 1747-1763, https://doi.org/10.1175/1520-0493(1992) $120<1747:$ TNMCSS $>2.0$. CO;2.

Qian, J. H., 2008: Why precipitation is mostly concentrated over islands in the Maritime Continent. J. Atmos. Sci., 65, 14281441, https://doi.org/10.1175/2007JAS2422.1.

Rashid, H. A., and A. C. Hirst, 2017: Mechanisms of improved rainfall simulation over the Maritime Continent due to increased horizontal resolution in an AGCM. Climate Dyn., 49, 1747-1764, https://doi.org/10.1007/s00382-016-3413-z.

Rauniyar, S. P., A. Protat, and H. Kanamori, 2017: Uncertainties in TRMM-era multisatellite-based tropical rainfall estimates over the Maritime Continent. Earth Space Sci., 4, 275-302, https://doi.org/10.1002/2017EA000279.

Roberts, N. M., and H. W. Lean, 2008: Scale-selective verification of rainfall accumulations from high-resolution forecasts of convective events. Mon. Wea. Rev., 136, 78-97, https://doi.org/10.1175/ 2007MWR2123.1.

Sakurai, N., and Coauthors, 2005: Diurnal cycle of cloud system migration over Sumatera Island. J. Meteor. Soc. Japan, 83, 835-850, https://doi.org/10.2151/jmsj.83.835.

— systems with diurnal cycle over Sumatera Island during CPEA-I campaign. J. Meteor. Soc. Japan, 87, 157-170, https:// doi.org/10.2151/jmsj.87.157.

Sato, T., H. Miura, M. Satoh, Y. N. Takayabu, and Y. Wang, 2009: Diurnal cycle of precipitation in the tropics simulated in a global cloud-resolving model. J. Climate, 22, 4809-4826, https://doi.org/10.1175/2009JCLI2890.1. 
Schwartz, C. S., and Z. Liu, 2014: Convection-permitting forecasts initialized with continuously cycling limited-area 3DVAR, ensemble Kalman filter, and "hybrid" variational-ensemble data assimilation systems. Mon. Wea. Rev., 142, 716-738, https://doi.org/10.1175/MWR-D-13-00100.1.

Sharpe, M. C., 2007: Incrementing liquid and frozen cloud water and grid-box cloud fractions for VAR observation operators and UM initialisation. VAR Scientific Documentation Paper 61, Met Office, $21 \mathrm{pp}$.

Sun, Q., T. Vihma, M. O. Jonassen, and Z. Zhang, 2020: Impact of assimilation of radiosonde and UAV observations from the Southern Ocean in the Polar WRF model. Adv. Atmos. Sci., 37, 441-454, https://doi.org/10.1007/ s00376-020-9213-8.

Takayabu, Y. N., and M. Kimoto, 2008: Diurnal march of rainfall simulated in a T106 AGCM and dependence on cumulus schemes. J. Meteor. Soc. Japan, 86A, 163-173, https://doi.org/ 10.2151/jmsj.86A.163.

Teo, C. K., T. Y. Koh, J. Chun-Fung Lo, and B. Chandra Bhatt, 2011: Principal component analysis of observed and modeled diurnal rainfall in the Maritime Continent. J. Climate, 24, 4662-4675, https://doi.org/10.1175/2011JCLI4047.1.

Tompkins, A. M., 2001: Organization of tropical convection in low vertical wind shears: The role of water vapor. J. Atmos. Sci., 58, 529-545, https://doi.org/10.1175/1520-0469(2001)058<0529: OOTCIL $>2.0 . C O ; 2$.

Vernimmen, R. R. E., A. Hooijer, N. K. Mamenun, E. Aldrian, and A. Van Dijk, 2012: Evaluation and bias correction of satellite rainfall data for drought monitoring in Indonesia. Hydrol. Earth Syst. Sci., 16, 133-146, https://doi.org/10.5194/hess-16133-2012.
Wang, Y., L. Zhou, and K. Hamilton, 2007: Effect of convective entrainment/detrainment on the simulation of the tropical precipitation diurnal cycle. Mon. Wea. Rev., 135, 567-585, https://doi.org/10.1175/MWR3308.1.

Wu, P., M. Hara, J. I. Hamada, M. D. Yamanaka, and F. Kimura, 2009: Why a large amount of rain falls over the sea in the vicinity of western Sumatra Island during nighttime. J. Appl. Meteor. Climatol., 48, 1345-1361, https://doi.org/10.1175/ 2009JAMC2052.1.

Yanase, A., K. Yasunaga, and H. Masunaga, 2017: Relationship between the direction of diurnal rainfall migration and the ambient wind over the Southern Sumatra Island. Earth Space Sci., 4, 117-127, https://doi.org/10.1002/2016EA000181.

Yang, G. Y., and J. Slingo, 2001: The diurnal cycle in the tropics. Mon. Wea. Rev., 129, 784-801, https://doi.org/10.1175/15200493(2001)129<0784:TDCITT>2.0.CO;2.

Yokoi, S., S. Mori, M. Katsumata, B. Geng, K. Yasunaga, F. Syamsudin, and K. Yoneyama, 2017: Diurnal cycle of precipitation observed in the western coastal area of Sumatra Island: Offshore preconditioning by gravity waves. Mon. Wea. Rev., 145, 3745-3761, https://doi.org/10.1175/MWR-D-16-0468.1.

Yoneyama, K., and C. Zhang, 2020: Years of the Maritime Continent. Geophys. Res. Lett., 47, e2020GL087182, https:// doi.org/10.1029/2020GL087182.

Žagar, N., N. Gustafsson, and E. Källén, 2004a: Variational data assimilation in the tropics: The impact of a background-error constraint. Quart. J. Roy. Meteor. Soc., 130, 103-125, https:// doi.org/10.1256/qj.03.13.

- - - , and,$- 2004 \mathrm{~b}$ : Dynamical response of equatorial waves in four-dimensional variational data assimilation. Tellus, 56A, 29-46, https://doi.org/10.1111/j.1600-0870.2004.00036.x. 